\title{
Urban Collage and the Tectonic Landscape
}

\author{
By
}

Erik Rossmann, B.A.S.

\author{
A thesis submitted to \\ The faculty of graduate studies \\ In partial fulfillment of \\ The requirements for the degree of
}

\section{MASTER OF ARCHITECTURE \\ M. Arch (professional)}

\author{
Carleton University \\ OTTAWA, Ontario \\ May, 2008
}

(C) Erik Rossmann, 2008 


$\begin{array}{ll}\begin{array}{l}\text { Library and } \\ \text { Archives Canada }\end{array} & \begin{array}{l}\text { Bibliothèque et } \\ \text { Archives Canada }\end{array} \\ \begin{array}{l}\text { Published Heritage } \\ \text { Branch }\end{array} & \begin{array}{l}\text { Direction du } \\ \text { Patrimoine de l'édition }\end{array} \\ \begin{array}{l}\text { 395 Wellington Street } \\ \text { Ottawa ON K1A ON4 }\end{array} & \begin{array}{l}\text { 395, rue Wellington } \\ \text { Ottawa ON K1A ON4 } \\ \text { Canada }\end{array}\end{array}$

Your file Votre référence ISBN:

Our file Notre reterence ISBN:

NOTICE:

The author has granted a nonexclusive license allowing Library and Archives Canada to reproduce, publish, archive, preserve, conserve, communicate to the public by telecommunication or on the Internet, loan, distribute and sell theses worldwide, for commercial or noncommercial purposes, in microform, paper, electronic and/or any other formats.

The author retains copyright ownership and moral rights in this thesis. Neither the thesis nor substantial extracts from it may be printed or otherwise reproduced without the author's permission.
AVIS:

L'auteur a accordé une licence non exclusive permettant à la Bibliothèque et Archives Canada de reproduire, publier, archiver, sauvegarder, conserver, transmettre au public par télécommunication ou par l'Internet, prêter, distribuer et vendre des thèses partout dans le monde, à des fins commerciales ou autres, sur support microforme, papier, électronique et/ou autres formats.

L'auteur conserve la propriété du droit d'auteur et des droits moraux qui protège cette thèse. $\mathrm{Ni}$ la thèse ni des extraits substantiels de celle-ci ne doivent être imprimés ou autrement reproduits sans son autorisation.
In compliance with the Canadian Privacy Act some supporting forms may have been removed from this thesis.

While these forms may be included in the document page count, their removal does not represent any loss of content from the thesis.
Conformément à la loi canadienne sur la protection de la vie privée, quelques formulaires secondaires ont été enlevés de cette thèse.

Bien que ces formulaires aient inclus dans la pagination, il n'y aura aucun contenu manquant. 


\section{TABLE OF CONTENTS}

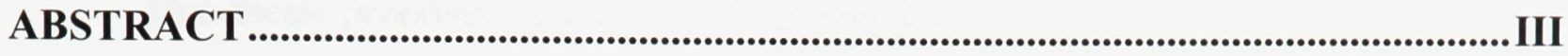

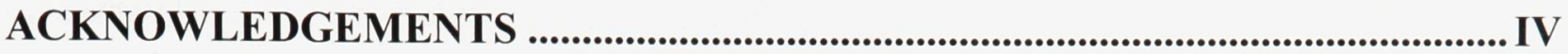

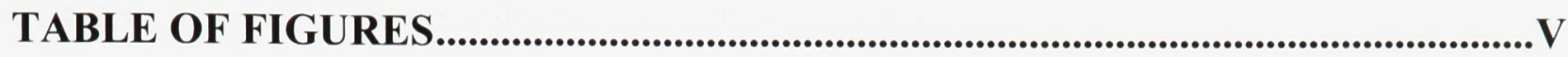

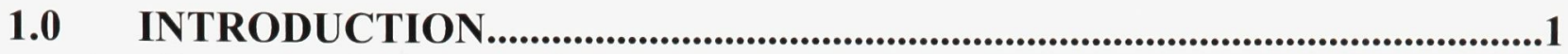

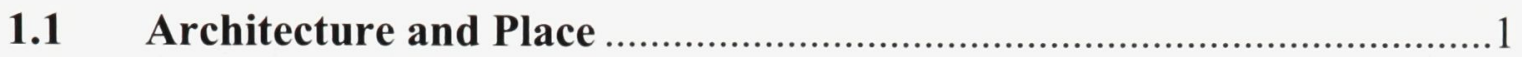

1.2 Ottawa's Genius Loci and the Tectonic Landscape .............................4

1.3 A Collage within a Collage ............................................................ 10

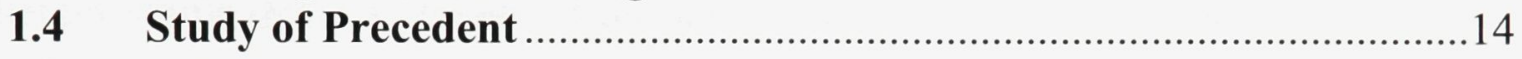

2.0 PHYSICAL AND HISTORICAL CONTEXT .................................................

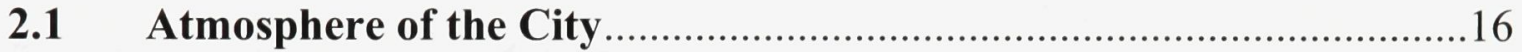

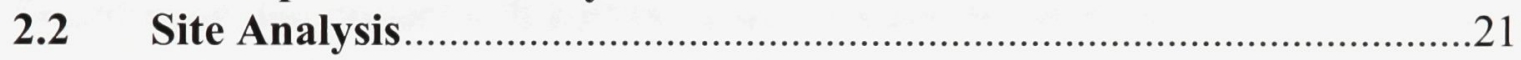

2.21 Urban Integration and Urban Developments ...............................21

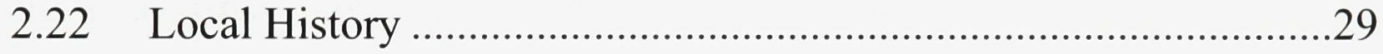

3.0 CULTURAL AND ENVIRONMENTAL BENEFITS .......................................33

3.1 Scope Tectonics in Ottawa's Cultural Landscape ……........................ 33

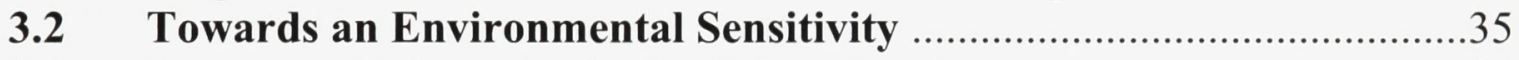

3.3 Traces and Memories in the Urban Landscape ……………...............44

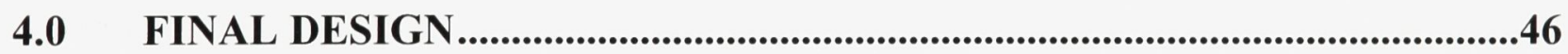

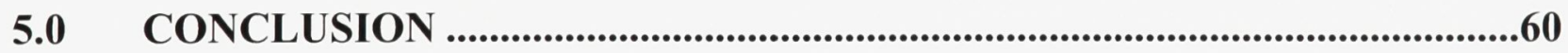

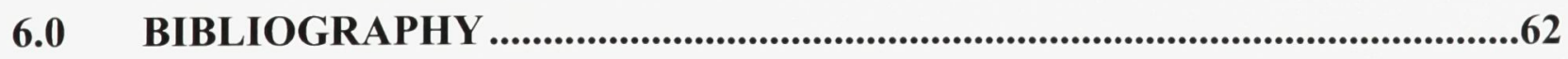

APPENDIX 


\begin{abstract}
This thesis proposes that a region's genius loci is based not on a single historical or cultural movement but on an eclectic collage of various historical ideologies. It argues that the strength of an architecture which is based a region's genius loci depends not on the strength of individual histories but on the dialogue between the different movements and an architect's ability to articulate the arising tension. The ideology will be tested through an urban design which seeks to bring historical fragments to an understandable and coherent whole using a collage of the ideologies inherent to the fragments and their present context. The hypothesis will then be evaluated through the project's ability to respond to current civic needs without loosing the strength of the individual pieces.

Specifically, the project will address a site in a pivotal location on Lebreton Flats, Ottawa. The site is an urban junction between downtown Ottawa, downtown Gatineau, the Capital's Park and the newly developed Lebreton Flats Community through a convergence of bicycle paths, walkways, and roads, notably Confederation Boulevard. The site will be developed into a as a continuous man-made landscape composed of buildings and piazzas using an eclectic combination of two prominent, complementary yet opposing approaches to architecture and landscape in Ottawa's history. The first is the approach taken by the industrial builders who saw the local landscape as a source of construction materials and energy. The second is the approach taken by the NCC who saw the local landscape as a place for natural splendor pastoral views. The new landscape and buildings will serve as a node for non-motorized circulation, a community center, and an urban theater shared between the Lebreton Flats community and the surrounding municipalities.
\end{abstract}




\section{ACKNOWLEDGEMENTS}

I would like to thank my advisor John Cook for his time, patience, advice, and challenging questions

I would like to thank my parents and my wife Sara for their constant support, unconditional love, and everyday inspiration

I would also thank my uncle Gert for me showing the joy of a career in architecture 


\section{TABLE OF FIGURES}

Figure 1- Thompson Perkins Mill, by author

Figure 2- $\quad$ Old Carbide Mill, by author

Figure 3- $\quad$ Photographs of Parliament Hill, by author

Figure 4- $\quad$ Photographs of Canadian War Museum, courtesy of Moriyama Teshima Architects

Figure 5- $\quad$ Images Showing the Site and the Thompson-Perkins Mill, by Author

Figure 6- Drawing and photographs of the Thomas Perkins Mill showing the yard main building as negative and positive relief in the site's man-mediated topography

Figure 7- Photograph of Tectonic Plan Collage Showing the existing conditions of the site, by author

Figure 8- $\quad$ Drawing showing circulation though upper datum

Figure 9- Drawing showing circulation through lower datum

Figure 10- Photographs showing contrast in materiality between Vancouver and Ottawa

Figure 11- Map the site, Victoria and Chaudiere Islands and Photographs of buildings built from local materials

Figure 12- Photograph of Gatineau home with finishes mimicking load bearing masonry construction

Figure 13- $\quad$ Auto-Cad Plan of the Site Showing the Ottawa River and the Parkway to the South, courtesy of City of Ottawa

Figure 14- Aerial photograph of the site in context

Figure 15- Image of the Site within Confederation Boulevard

Figure 16- Rendering Showing Future Developments by Claridge Homes. Courtesy of NCC

Figure 17- $\quad$ Photograph of the ramp descending from the Parkway into the site

Figure 18- $\quad$ Photograph of the tunnel connecting the site to the bicycle leading to the pumping station and center town

Figure 19- Photograph of the small hydro electric dam and a walkway currently used by employees Figure 20- Photograph of the load bearing structure built of locally quarried Nepean Limestone 
Figure 21- Steel framework structure cantilevers over the river using the stone walls as a cliff

Figure 22- $\quad$ Non Motorized Urban Circulation and convergence at the site

Figure 23- Site Plan with Annotated building Pavilions

Figure 24- $\quad$ Annotated site plan and model showing the use of the site as a public theater defined by the Parkway and Ottawa River

Figure 25- Model Photograph showing the topographical form of the buildings and outdoor platforms of the viewing area

Figure 26- Ice Hockey rink in the central court during winter

Figure 27- Elevation and Section Through pavilion 2

Figure 28- Section Detail of the transition from earth and sky through the Retaining wall and roof.

Figure 29- Section Showing Passage over the dam and under the Main Terrace

Figure 30- Elevation of Pavilion 3 showing green roof and lookout points to the right

Figure 31- Model photograph showing the cantilever dining terrace and new walkway along the water using the masonry walls as a cliff

Figure 32- $\quad$ Plans of Pavilions 1 and 2 showing dialogue of structural construction and circulation

Figure 33- Plans of Pavilions 1and 2 showing dialogue of structural construction and circulation

Figure 34- Model photograph of Pavilions 1 and 2 showing the dialogue of construction logic of industrial interventions and the NCC's landscape embellishment movement

Figure 35- Detail Section of the small theater and former yard

Figure 36- Photograph of the small theater (former work yard) 


\subsection{INTRODUCTION}

\subsection{Architecture and Place}

The desire to reconnect architecture to place and reestablish a connection with local environment, tradition and history is not a new one. In fact, critical regionalism is a movement that extends far beyond architecture and includes disciplines from philosophy to the culinary arts in a movement known as slow food. ${ }^{1}$ During the early days of modernism, many avant-garde architects supported the creation of an international style and the severance of ties to history and regional cultures. Today, innovative designers such as Renzo Piano have the opposite goal in restoring a sense of place to architecture by relating to its region's environment and history ${ }^{2}$. Architecture respectful of a region's genius loci or spirit of place has benefits such as a strengthened socio-cultural identity ${ }^{3}$ and a construction that is friendlier to the environment ${ }^{4}$.

In its early days, Ottawa like many Canadian cities was just a small town of lumber barons and a sort of industrial backyard to Europe. Builders did not have the means or motivation to create architecture with the craft and artistic finesse that was common in major European cities. Much of the city's old masonry architecture was built from locally quarried stone and left in a relatively raw state in order to save money on

\footnotetext{
${ }^{1}$ Slow Food International Website. Accessed April13, 2008 http://www.slowfood.com/about_us/eng/philosophy.

${ }^{2}$ Peter Buchanan, Renzo Piano Building Workshop Complete Works Volume 2, London: Phaidon Press Limited, 1995, p.190

${ }^{3}$ Kenneth Frampton, "Towards a Critical Regionalism, Six Points for Architecture of Resistance". Labour, Work, and Architecture, London: Phaidon Press, 2002, p.81

${ }^{4}$ Kenneth Frampton, Towards a Critical Regionalism, "Six Points for an Architecture of Resistance". Labour, Work, and Architecture, London: Phaidon Press, 2002, p.86
} 
transportation and labor. ${ }^{5}$ As a result many of the buildings have a visual relationship to their natural surroundings and can be recognized as a man-mediated extension of the landscape itself.

A later movement overseen by the NCC, seeking to embellish the capital by drawing attention to Canadians' integration with nature made further interventions upon the landscape through pedestrian paths, trees, and a pastoral waterfront promenade known as the Ottawa River Parkway. In some cases, traces of industrial architecture overlap with those of the NCC movement and create an interesting dialogue as the interventions of both historical periods have a strong relationship with the surrounding landscape. While the industrial builders saw the local landscape as a source of construction materials and energy, the NCC saw it as a place for natural splendor and pastoral views.

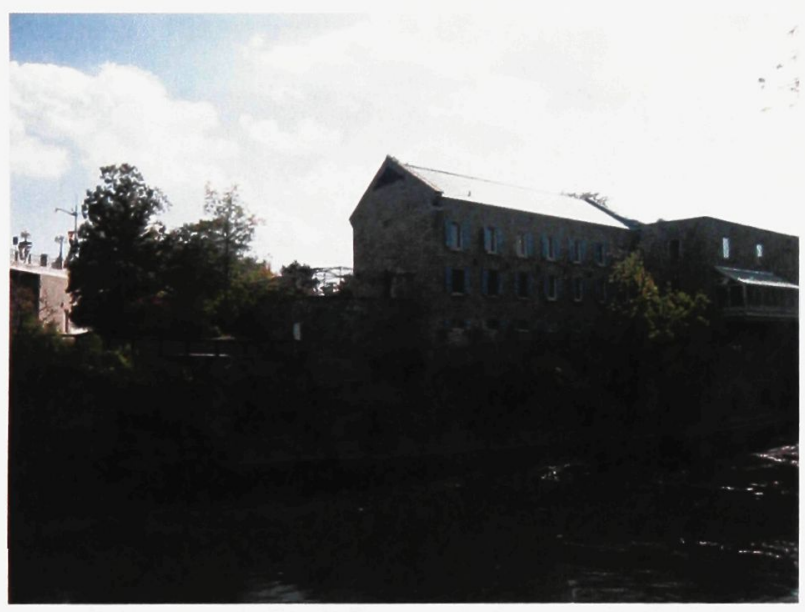

Figure 1. Thompson Perkins Mill, by author

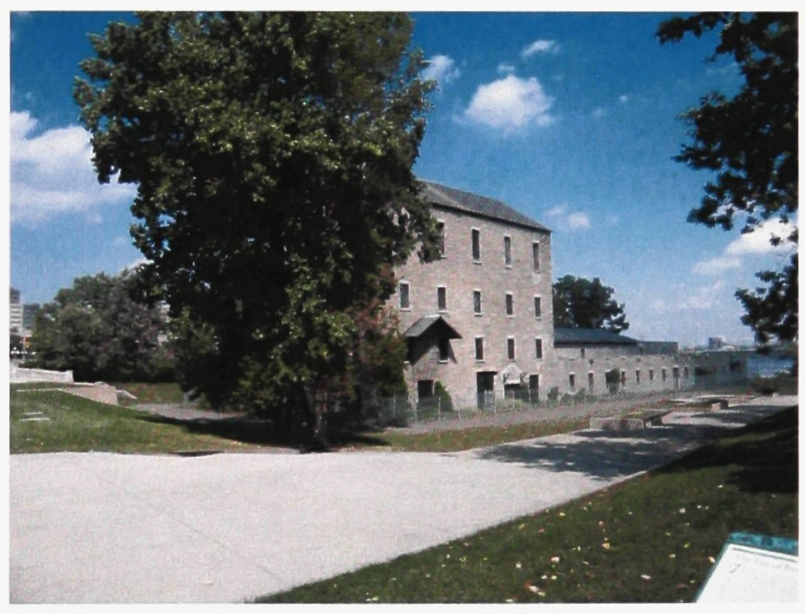

Figure 2. Old Carbide Mill, by author

These images of the Old Thomson-Perkins Grist Mill and the Old Carbide Mill are examples of an overlap between Industrial construction using locally quarried limestone

\footnotetext{
${ }^{5}$ KWC Architects Inc, National Capital Commission, Building Condition Assessment Report : Thomas Perkins Mill, (The Old Mill), Ottawa, 2007, p.1
} 
and a controlled reinvasion by natural elements implemented by the NCC to embellish the City along waterfronts and ceremonial routes. ${ }^{6}$ The overlap of architecture built from the surrounding landscape and the reintroduction of the natural landscape into the existing architecture illustrates an interesting dialogue of tensions between the two ideologies and their relationship to the landscape.
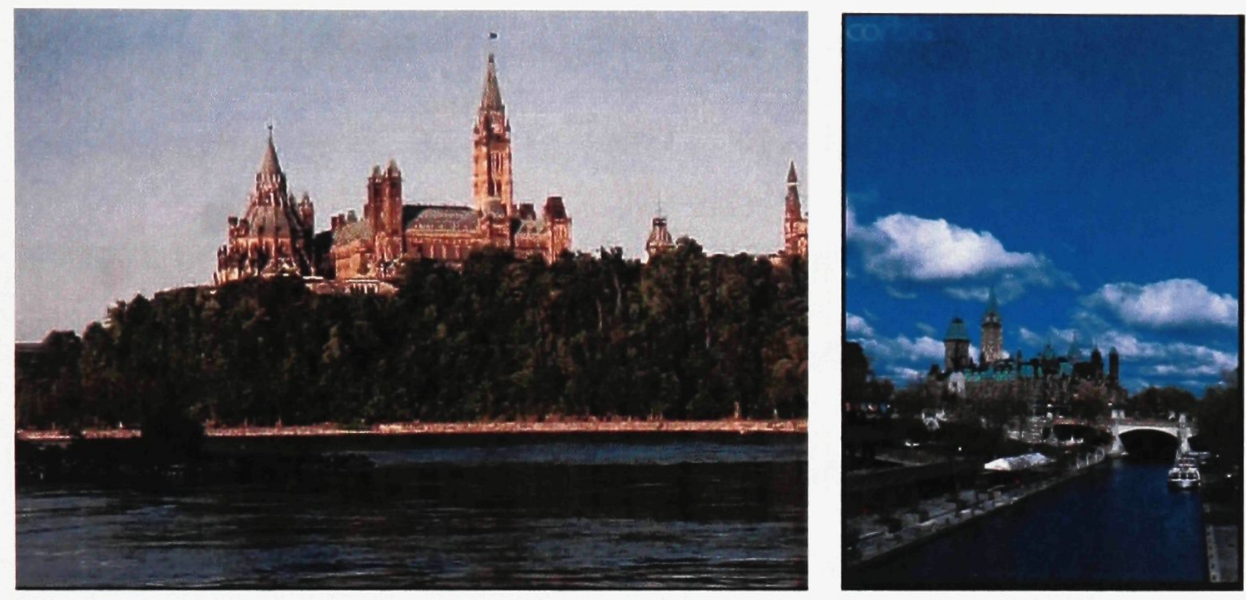

Figure 3. Photographs of Parliament Hill
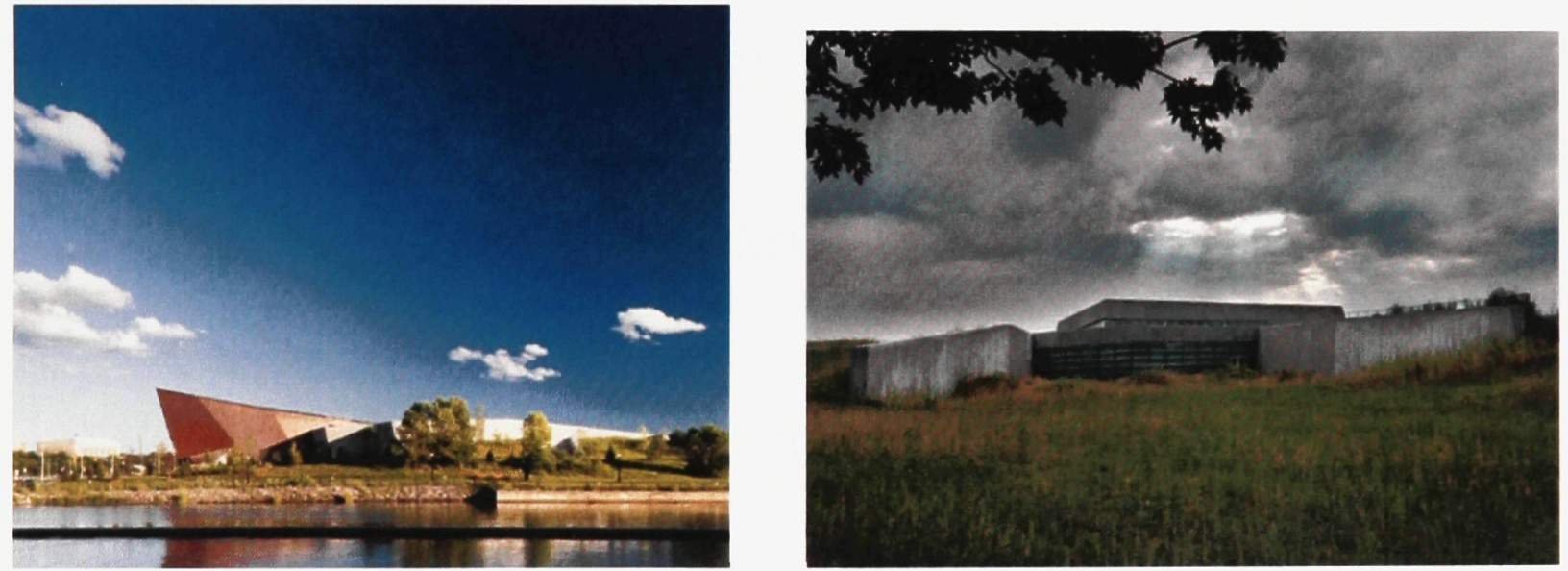

Figure 4-Photographs of Canadian War Museum, courtesy of Moriyama Teshima Architects

I believe these images of the Parliament buildings and the War Museum show how an architecture that relates to Ottawa's vernacular industrial architecture through

\footnotetext{
${ }^{6}$ All About The City Of Ottawa Website, accessed November 14, 2007. < http://www.teskey.com/ottawa/>
} 
heavy earthwork interventions and to the NCC's pastoral approach to landscape through their integration of indigenous flora. In both buildings, the museum and the parliament, the architecture is made of heavy earthwork interventions on the landscape and a carefully planned reinvasion the buildings by living landscape elements.

By treating the design of landscape and building equally in architecture and applying both of the identified logics of construction, building into the local natural landscape and integrating existing and proposed buildings into it, I hope to find an architecture that is more indigenous its environment, more sensitive to the cultural context, and provides a better place for social exchange.

\subsection{Ottawa's Genius Loci and the Tectonic Landscape}

My interest in this subject originated in the structural and tectonic culture of architecture and the methods used in vernacular construction that express contextual ideas and respond to local conditions. This drew me to investigate aspects of architecture's technical assemblage and its connection to place. At one point in time, buildings were naturally connected to their place of construction as the absence of industrialized transportation and the difficulty of shipping materials through preindustrial means encouraged architects and builders to work with locally available resources.

In the past, the place was the obvious presence that transmitted identity to its inhabitants. It was not necessary therefore to develop a theory of place; concrete action was sufficient. This common opinion was handed down in vernacular architecture, even though the theory 
of architecture had become alienated from the world of life. ${ }^{7}$

This quote by Norberg-Shultz addresses the loss of identity in cities through the arrival of placeless architecture. Although place-connected architecture is possible today, as Norberg Shultz states, it is no longer achievable through concrete actions alone the way it was in vernacular architecture. Instead, there must be a more conscious implementation of the local spirit. The reason why the architect's and builder's concrete actions and pragmatic design no longer suffice in the creation of place-specific architecture are complex and numerous. Two important factors are the separation of architecture from construction and the loss of regional traditions in most of the construction industry. ${ }^{8}$

The first factor, separation of architecture and construction, can be observed in academia, offices, and construction sites. In the vernacular architecture that Norberg Shultz was referring to, the processes of design and construction were far more integrated. The majority of vernacular architecture in Ottawa and elsewhere stems from traditions based on construction techniques passed on from father to son using regional methods and materials. Architects, at one time fully integrated in the construction process, were committed to the regional techniques and would conceive architecture connected to place as they were in constant contact with local craftsmen and builders. ${ }^{9}$ As architects continued to build according to local traditions, a tectonic culture was born. This tectonic culture changed and evolved with the other facets of a region's culture to which it continuously adapted. Today, due to the separation of architecture from construction, most architects have little exposure to local traditions and techniques. For

\footnotetext{
${ }^{7}$ Christian Norberg-Shultz, Architecture: Presence, Language, Place. Milano, Italy: Skira, 2000 p. 28.

${ }^{8}$ Kenneth Frampton, "Towards a Critical Regionalism, Six Points for an Architecture of Resistance". Labour, Work, and Architecture, London: Phaidon Press, 2002, p.78

${ }^{9}$ Kenneth Frampton, "The Owl of Minerva”, Studies in Tectonic Culture. London: MIT Press, 1995, p. 381
} 
this reason, the relationship between architectural tectonics and their place of construction has weakened. ${ }^{10}$ The second factor, the separation of construction and local tradition, can largely be attributed to the emergence of industrially manufactured building products and imported/exported materials. ${ }^{11}$ The use of local materials and methods was naturally encouraged in the past as importing and exporting over large distances was far more costly than using local resources. Also, the huge cost increase of skilled local craft relative to industrial and third world production has all but eliminated the use of traditionally crafted local materials. As a result, today's architecture and construction no longer have the automatic connection to place as vernacular architecture had. Therefore, if they want architecture's connection to place to persist, architects and builders must make a conscious reference to the genius loci through an understanding of local history, environment, and climate. By researching the nature of Ottawa's genius loci I should be able to create architecture that responds to current urban conditions while maintaining the spirit of the city and its history.

My interest in reviving some of the tectonic relationships between building and place in Ottawa brought me to a small site in the north eastern corner of Lebreton Flats. The site is very rich with a sense of place due a number of traces and fragments left by the early days of industrialization in Canada. The part of the site that caught my eye the most was an old masonry building known formerly as the Thompson-Perkins Mill. Although it was originally built for industrial purposes, this building is a representation of

\footnotetext{
${ }^{10}$ Vitruvius Pollio-translation by Ingrid D. Rowland, Vitruvius: The Ten Books on Architecture, New York Cambridge University Press, 1999.

${ }^{11}$ Kenneth Frampton, "Towards a Critical Regionalism, Six Points for an Architecture of Resistance". Labour, Work, and Architecture, London: Phaidon Press, 2002, pp. 77-84
} 
Norberg Shultz's statement regarding vernacular architecture built with a sense of place without intentional effort.
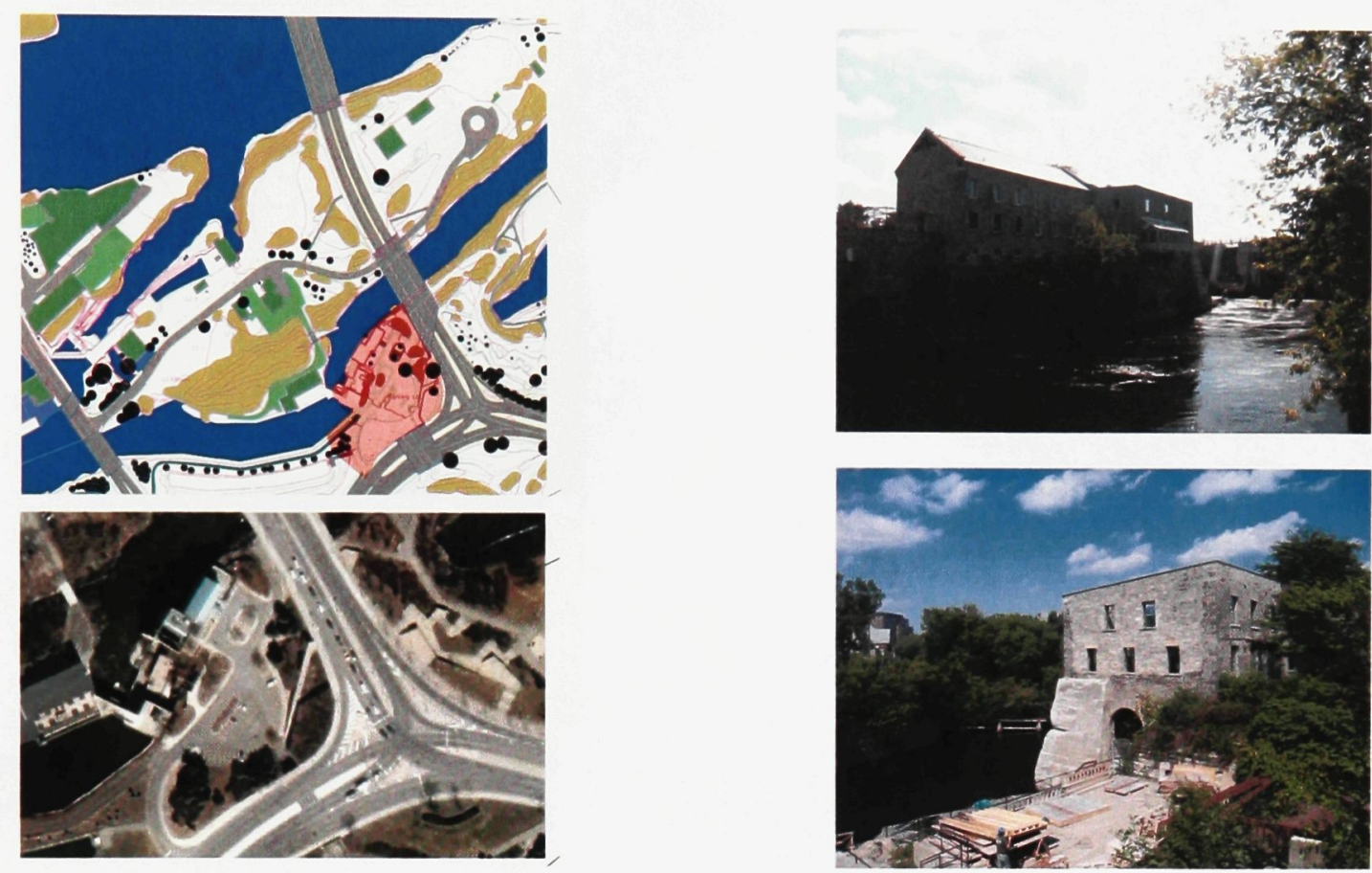

Figure 5. Images Showing the Site and the Thompson-Perkins Mill, by Author

The building is constructed out of the same type of Nepean limestone that lies beneath its foundation. ${ }^{12}$ In fact, an analysis of the building revealed that it was built as an extension of the landscape through a series of cuts, pours, and displacements of the site's underlying bedrock. For example, a section of the riverfront was carved out for limestone, which seems to have been used to construct the turbine room and main building. This carved portion of the shore now lies much closer to the river and was long used as an outdoor yard for work and storage. Both the yard and buildings now form negative and positive relief in the site's man-mediated topography.

\footnotetext{
${ }^{12}$ KWC Architects Inc, National Capital Commission, Building Condition Assessment Report : Thomas Perkins Mill, (The Old Mill), Ottawa, 2007, p.4-7
} 

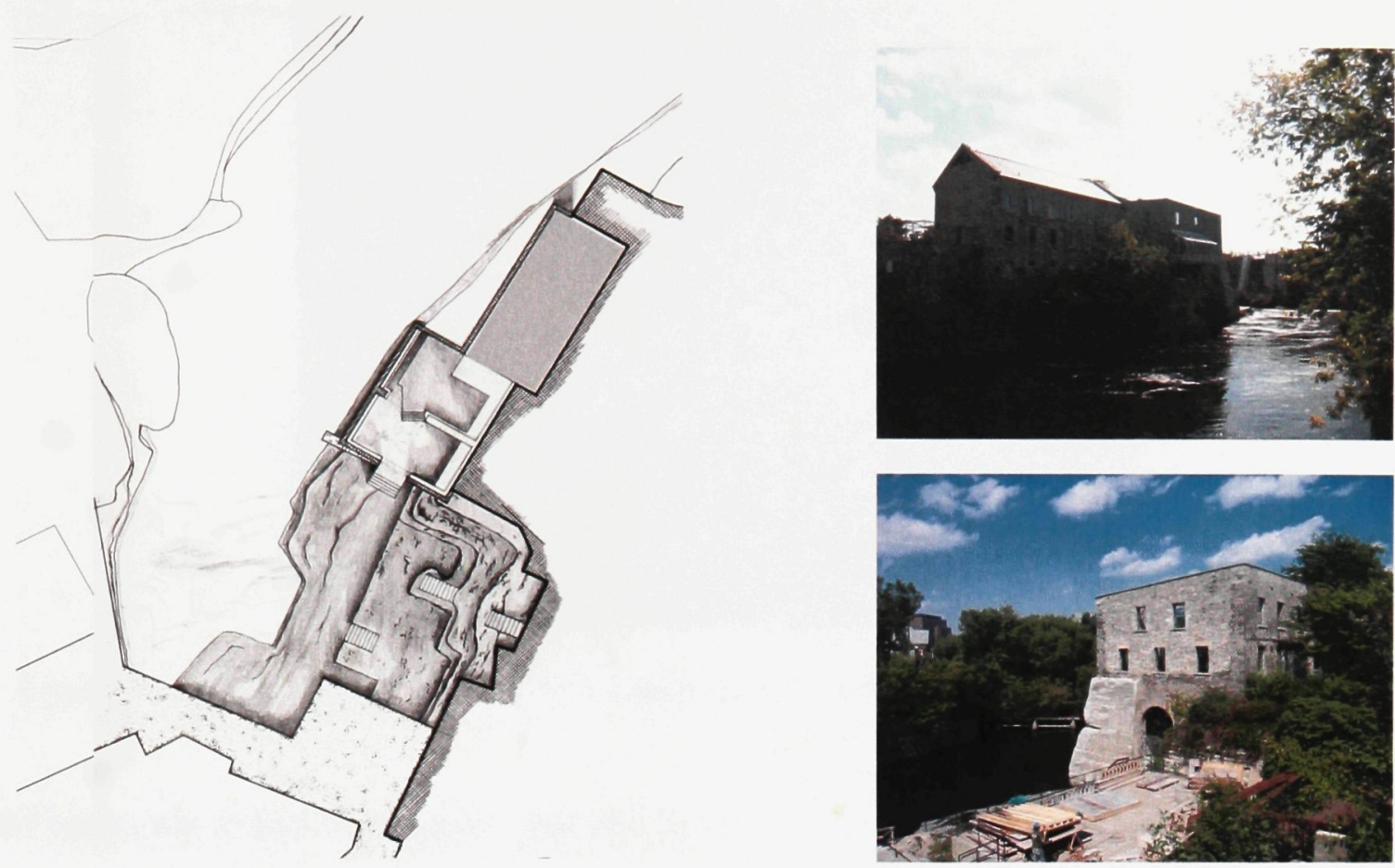

Figure 6. Drawing and photographs of the Thomas Perkins Mill showing the yard main building as negative and positive relief in the site's man-mediated topography

In order to fully understand the site in three dimensions, I abstracted plans into an architectural model. (See image below) Using a combination of woods helped me analyze the site as one entity where the buildings, excavations, and other landscape elements can all be understood as part of a continuous man-mediated topography. I used the same plywood to represent both the buildings and the bedrock out of which they were built. The stratification and natural wood grain of the plywood represent the geological layering and the raw stone masonry while the homogeneous grain of the MDF is used to represent the more uniform dams poured out of concrete. 


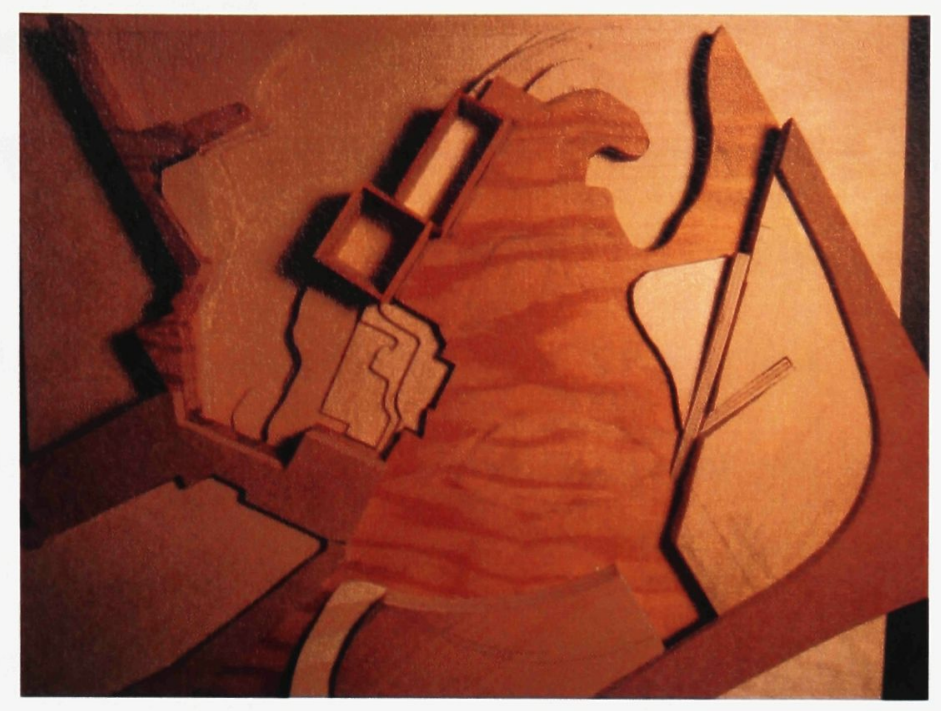

Figure 7. Photograph of Tectonic Plan Collage Showing the existing conditions of the site

This study made me realize that the entire site could be explored architecturally. It is based on this realization that I left my abandoned my initial project of designing an addition to the existing building or new building adjacent to it. My current approach calls for continuous uninterrupted construction of buildings and landscape on the entire site while maintaining sensitivity to traces of the site's history. (See Appendix) I believe that by addressing landscape design and its materials within design of traditional architecture one will create architecture more respectful of local conditions since soils, trees, and grasses remain part of the local environment. Architectural structures which support flora must be designed specifically for the plants within their environmental context and will therefore also make a response to the place. This type of collage composed of historical fragments, traces, and erasures of architecture and landscape are what I coined the tectonic landscape. 


\subsection{A Collage within a Collage}

Like Colin Rowe's Collage City, this thesis is based on the concept of a city as a collage of meaningful fragments created by historical interventions over time which are then woven together through various networks and systems to form a complete picture. ${ }^{13}$ As a complete picture, a city provides elements for functional shelter, networks for circulation, and places for rest and contemplation within its fabric. As a collage within the greater collage of the city, the tectonic landscape operates both as connective tissue for other architecture as well as a space of contemplation and spectacle responding to urban needs. The tectonic landscape is also a collage of histories and ideologies. Both Rowe and Norberg Shultz state that new architecture conscientious of the past refers not to a single historical movement but rather to an eclectic collage of historical ideologies that are significant to a site and its context. In my case the collage's primary ideological pieces are the industrial exploitation of the riverfront and the movement of natural reintroduction by the NCC. Colin Rowe believed that modern architecture with severed ties to history would have destructive effects on the historical city ${ }^{14}$ while architecture referring exclusively to a single historical movement would lack sensitivity to present condition and other important historical movements. Additionally, given that Ottawa lacks the glorious history of many European cities, relying on the strength of a single historical movement for inspiration may suggest that new architecture in Ottawa cannot be as intense an experience as the new architecture of Paris or Rome. I believe the strategy of using an eclectic collage of pertinent local histories defies the limitations of a

\footnotetext{
${ }^{13}$ Colin Rowe and Fred Koetter, Collage City, Cambridge: MIT Press, 1978, p. 2-11.

${ }^{14}$ Colin Rowe and Fred Koetter, Collage City, Cambridge: MIT Press, 1978, p. 8.
} 
modest history as it depends not on the strength of the individual movements, but on the strength of dialogue and the level of tension between them.

One of the challenges faced by this project if it is to be successful in the creation of outdoor spaces is addressing the need for recreation, reflection, and social interaction in the daily lives of citizens. To do so effectively, outdoor urban spaces will be understood, treated, and built as spaces of equal historical and cultural weight as other institutional forms of architecture. Though spaces for social interaction and quiet contemplation were once abundant in western culture and remain common in older urban centers, these spaces are scarce or non existent in the younger North American cities. The causes for this change are numerous and consequences have been severe. Most causes responsible for the changes in our cities accompanied the introduction of technology during the industrial revolution, which in turn changed the pace of living. One if not the most important factor leading to the disappearance of contemplation and interaction in Western lifestyle has been the proliferation of motorized vehicles and the disappearance of the daily walk. In older cities, the architecture developed over time and the public spaces, streets and squares developed as buildings were destroyed to provide space for others. However, because cities such as Ottawa developed primarily after the rise of motorized transportation they were designed around the fast movement of roads and highways. ${ }^{15}$ However, in recent years, walking, cycling, and other non-motorized transportation regained popularity in an increasingly dense urban context and junctions such as this site have the opportunity to become spaces of contemplation and social

\footnotetext{
${ }^{15}$ Kenneth Frampton, Towards a Critical Regionalism, "Six Points for Architecture of Resistance". Labour, Work, and Architecture, London: Phaidon Press, 2002, pp. 77-86.
} 
interaction in the city through both movement and rest. The redesigned site will be rewoven into the contemporary urban fabric through small roads, walkways, and bicycle paths. The following site plan shows the non motorized circulation through the site on the upper level as it connects to sidewalks, Parkway, and a new walkway to Victoria Island via the old dam. It also shows circulation on the lower level as paths running through the inner court lead to Parliament Hill, Center Town, and the new community being developed on Lebreton Flats.

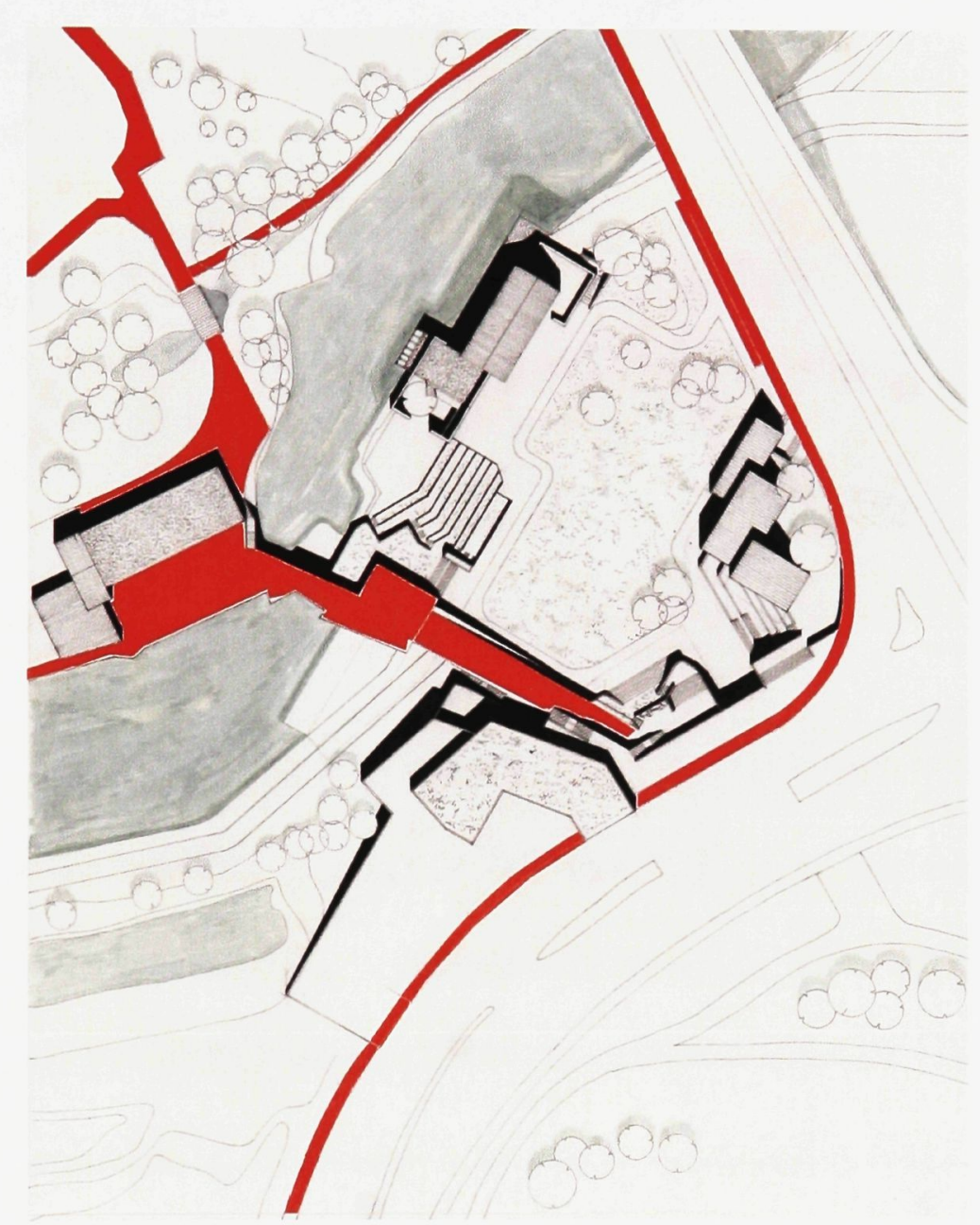

Figure 8 Drawing showing circulation though upper datum 


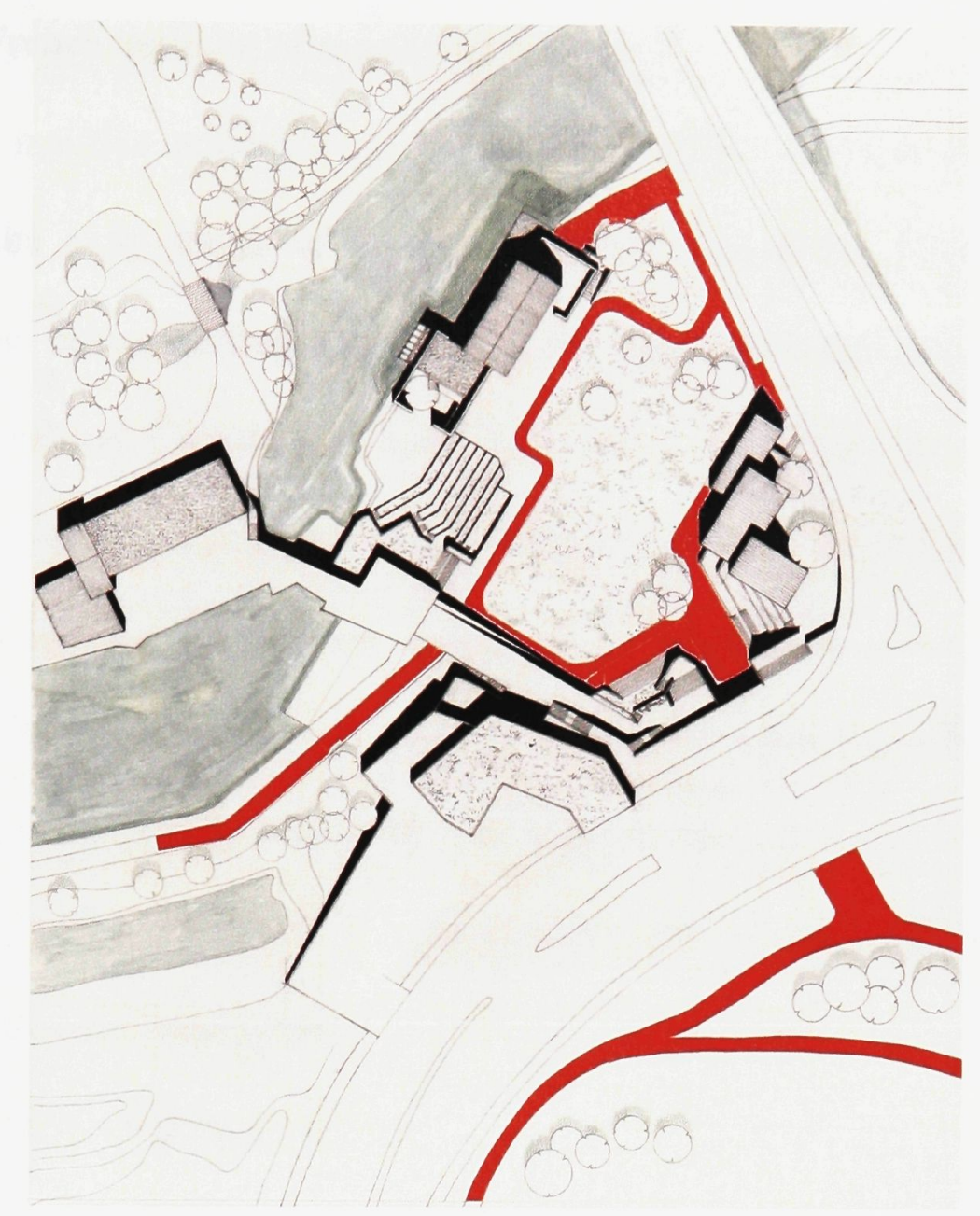

Figure 9 Drawing showing circulation through lower datum

As one looks at the site's planning, one becomes aware of a number of landscape interventions. These interventions are very different from those of the industrial age yet are equally significant and historically weighted. These heavy landscaping moves were made to the site during the mid-twentieth century to restore a sense of natural beauty to the site. Despite the appearance, like many of the lands surrounding Parliament Hill and the escarpment, this site was not left as a natural landscape. Rather, it was designed with heavy cultural and political weight as this style of landscape design is rooted in the English natural landscape style pioneered by Charles Bridgeman, which is in stark 
contrast to the French tradition of manicured gardens. ${ }^{16}$

These massive undertakings by the NCC reflect commonwealth lineage and coincide with the early stages of the environmental movement, posing an interesting tension with the industrial fragments. Both of these ideologies are important in the history of Ottawa and Canada and have left sites such as this one with an enriched cultural fabric. I intend to accord both historical influences their due place as part of an eclectic collage of ideas for the new design of the urban park and community center. Fragments of both the industrial colonization era and the urban beautification movement will be addressed respectfully within the new tectonic landscape which seeks to bring all fragments of the urban collage to an understandable and coherent whole without loosing the strength of the individual pieces.

\section{$1.4 \quad$ Study of Precedent}

Because the project is so heavily based on the genius loci of the specific site, it was impossible to use a precedent as framework. However, my understanding of architecture as a holistic collage of industrial fragments and landscape interventions was aided by my study of Duisburg North's Landscape Park. ${ }^{17}$

In his project, Peter Latz explores the pragmatic and conceptual advantages of using a contaminated industrial site for the development of a landscape architecture project as opposed to using a Greenfield site. By reintroducing organic elements into an obsolete group of buildings, Duisburg North re-evaluates the understanding of site, landscape, and architecture. A decontamination process is gradually taking place in Duisburg North

\footnotetext{
${ }^{16}$ Wikipedia, Charles Bridgeman, Accessed March 10, 2008, $<$ http://en.wikipedia.org/wiki/Charles_Bridgeman>

${ }^{17}$ University of Hong Kong, School of Architecture Website, accessed April 2006, available from: www.arch.hku.hk/teaching/cases/duisburg/Duisburg.htm
} 
trough a number of plants and trees which filter the waters and cleanse the soils of toxins which were left by industrial processes. My site is very different from Duisberg North as its scale is much smaller and the contamination has already been achieved. However Latz's work has helped me understand the architecture as an extension of landscape and landscape interventions as a piece of culture and history. The advantages of this logic are discussed in greater detail in section 3.0. 


\subsection{PHYSICAL AND HISTORICAL CONTEXT}

\subsection{Atmosphere of the City}

I have lived in Ottawa most of my life but have traveled frequently to other cities in North America as well as in Europe and in Asia. I have found that the cities endowed with the greatest architecture tend to be those with a strong historical fabric which is understood, celebrated, and used conceptually to create bold new architecture. Older, historically charged cities such as London, Paris, and Berlin are examples. By traveling and returning home, I have been able to identify certain characteristics about the city where I grew up. Ottawa tends to be a city that is architecturally conservative. A young city with a modest history may have a tendency to reproduce visual attributes of vernacular architecture in an attempt to strengthen its heritage. I have grown certain sympathy for this point of view without agreeing with it. I believe it is healthy for a city to cherish its history no matter how modest it may be and build in ways that respond to the local environment and traditions. Some of the advantages are a better sense of cultural identity and a way of building more friendlily to the environment. ${ }^{18}$ Unfortunately, visual reproductions of the vernacular often have the opposite effects, trivializing historical gems instead of drawing attention to them as when they reproduce visual attributes while lacking the tactile ${ }^{19}$ and spatial qualities. There is also a tendency to use wasteful amounts of valuable materials to simulate construction methods of the past.

\footnotetext{
${ }^{18}$ Kenneth Frampton, Towards a Critical Regionalism, "Six Points for an Architecture of Resistance". Labour, Work, and Architecture, London: Phaidon Press, 2002, p. 86

${ }^{19}$ Kenneth Frampton, Towards a Critical Regionalism, "Six Points for an Architecture of Resistance". Labour, Work, and Architecture, London: Phaidon Press, 2002, p.88
} 
As a native of the capital region, I hope this thesis will help me understand how to generate architecture more connected to the Ottawa region, where the history is not as obvious and famous as in other places of the world, yet where people and organizations such as the NCC show surprisingly strong attachment to historical buildings and a reluctance to embrace non-traditional architectural designs. ${ }^{20}$ As a citizen and an architect living in Ottawa, I wanted to understand the nature of the subconscious ideology behind the vernacular architecture to which people are attached. An understanding of the genius loci should enable me to create architecture that responds to current urban conditions while maintaining the spirit of the city and its history. This I hope to achieve without resorting to cosmetic reproductions of past building styles or reverting to nostalgic construction techniques.

Aside from the hesitance to embrace new styles, Ottawa is also architecturally conservative in the sense that the city bears an earthiness. Unlike cities such as New York, Vancouver, or Sydney, Ottawa is a city that exhibits inertia with regards to its environment. This atmospheric inertia is a distinctive quality of the traditional buildings in Ottawa made of local materials such as load bearing masonry and log. Cities of glass or white finishes reflect their environment, mirroring the conditions of the atmosphere. Although this phenomenon can be beautiful, modern skyscrapers are often criticized for their tendency of appearing as mysterious and intimidating trough their masses of reflective glazing. In Ottawa, these changes in atmosphere do occur, but as scattered reflections throughout the city's windows and bodies of water.

\footnotetext{
${ }^{20}$ Rhys Phillips, "Beautiful Fragments and Sterile Towers", The Ottawa Citizen, 2007, available from: $<$ http://www.thefulcrum.ca/node/1234>
} 

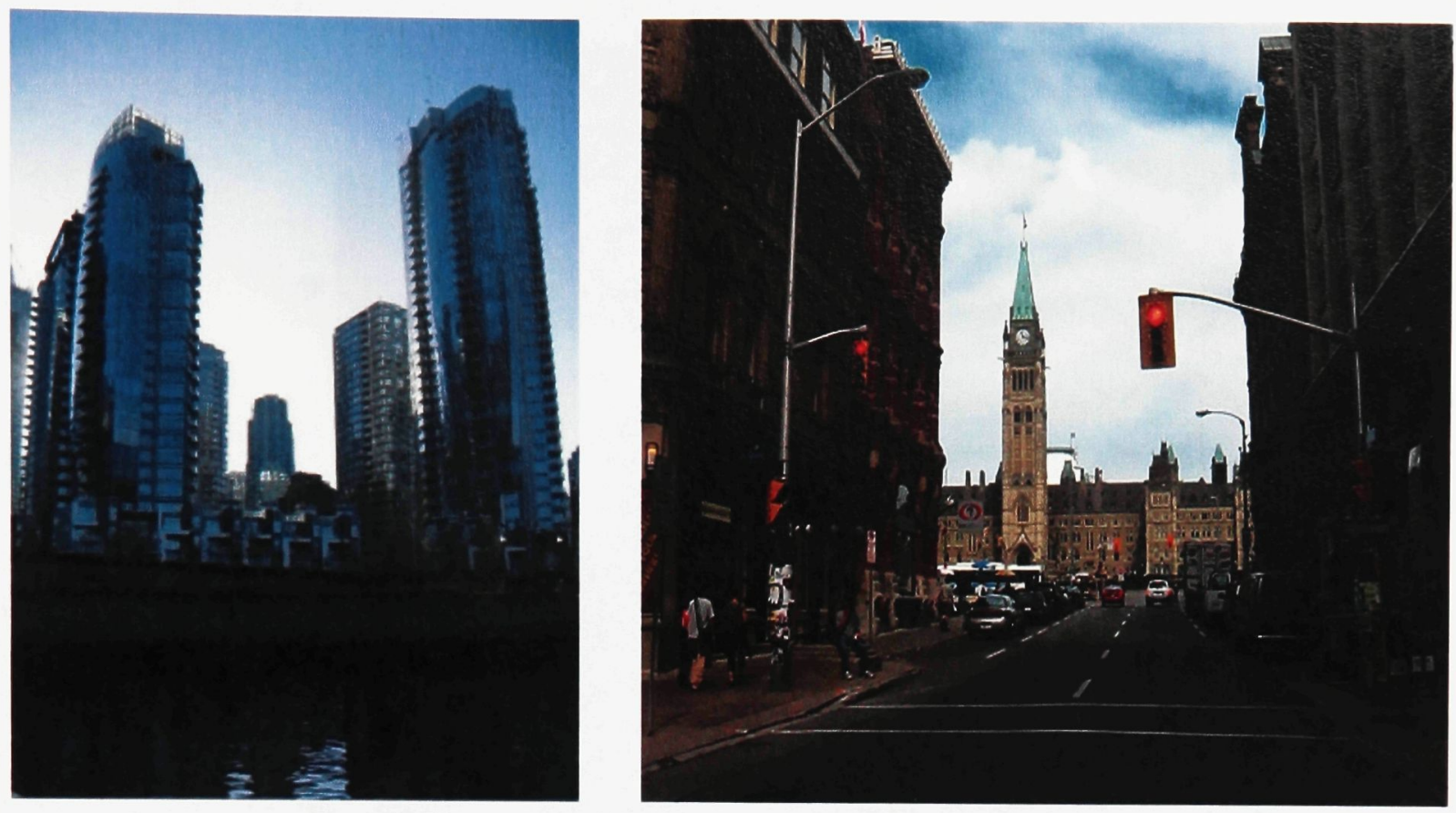

Figure 10. Photographs showing contrast in materiality between Vancouver and Ottawa

The buildings which set the cannon for this aspect of Ottawa's architecture's were built to serve the industry during the mid $19^{\text {th }}$ century ${ }^{21}$. Making use of local materials, these buildings were built primarily of local wood, brick, and masonry, thus avoiding large amounts of glitter. The images below show a number of such buildings that were built with materials from the direct vicinity of their construction site and the surrounding landscape. Most of the original buildings of this earthy, regional character are found in the general region surrounding Lebreton Flats, Chaudiere, and Victoria islands (shown on the map on the lower left).

\footnotetext{
${ }^{21}$ Shannon Basset, "Logjammed", Canadian Architect, January 2007. Accessed March, 2008. Available from:

$<$ http://www.canadianarchitect.com/issues/ISarticle.asp?id=183232\&story_id=198722134700\&issue=0101 $2007 \& \mathrm{PC}=\& \mathrm{RType}=>$
} 


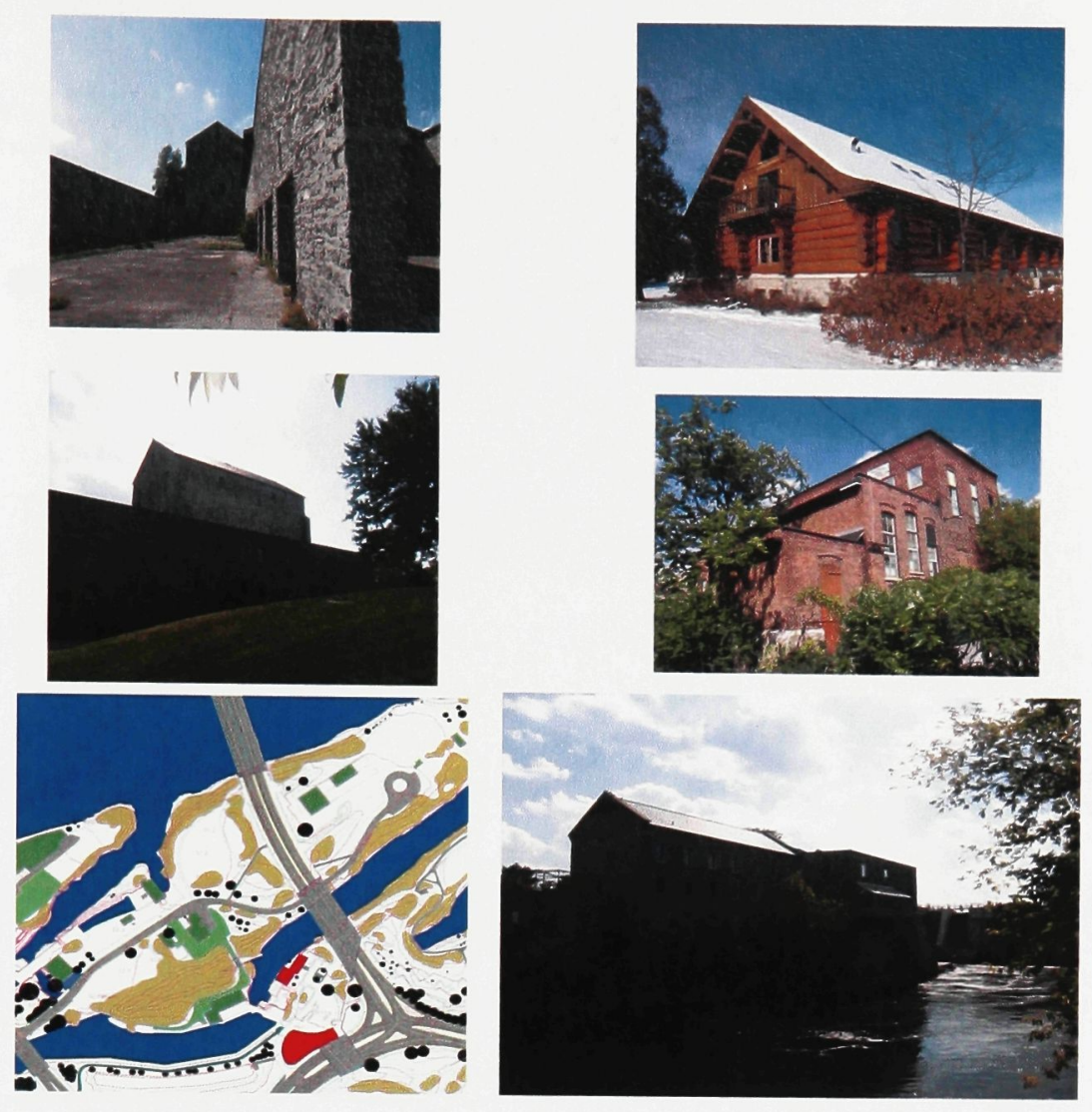

Figure 11. Map the site, Victoria and Chaudiere Islands and Photographs of buildings built from local materials

These buildings have a strong sense of place to the capital region and their feel of earthiness has been than successfully been reproduced in recent years. Because we can no longer have buildings of non insulated, exposed structural materials, certain architects and builders try to imitate the appearance of these building's by using cladding materials reminiscent of structural materials of the past. 


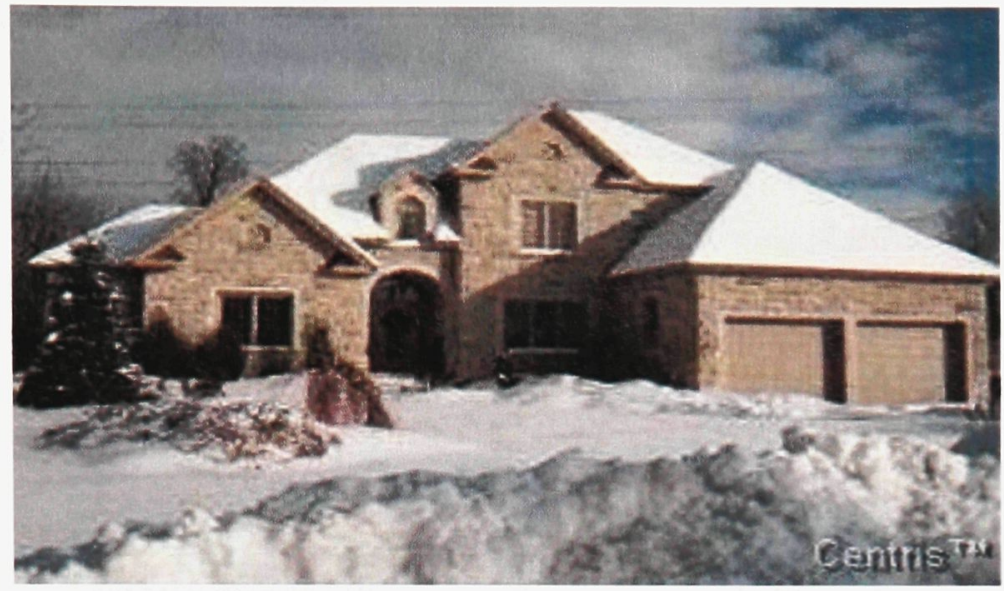

Figure 12. Photograph of Gatineau home with finishes mimicking load bearing masonry construction

As I mentioned previously, the result is often disappointing: wasteful and pretentious imitations of the past. These types of buildings are deceptive to the untrained eye of the layman and an insult to trained eye of the professional. The tectonic landscape approach proposes a conceptual reference to regional and historical construction logics without visual pretence of nostalgic techniques. 


\subsection{Site Analysis}

\subsection{Urban Integration and Current Developments}

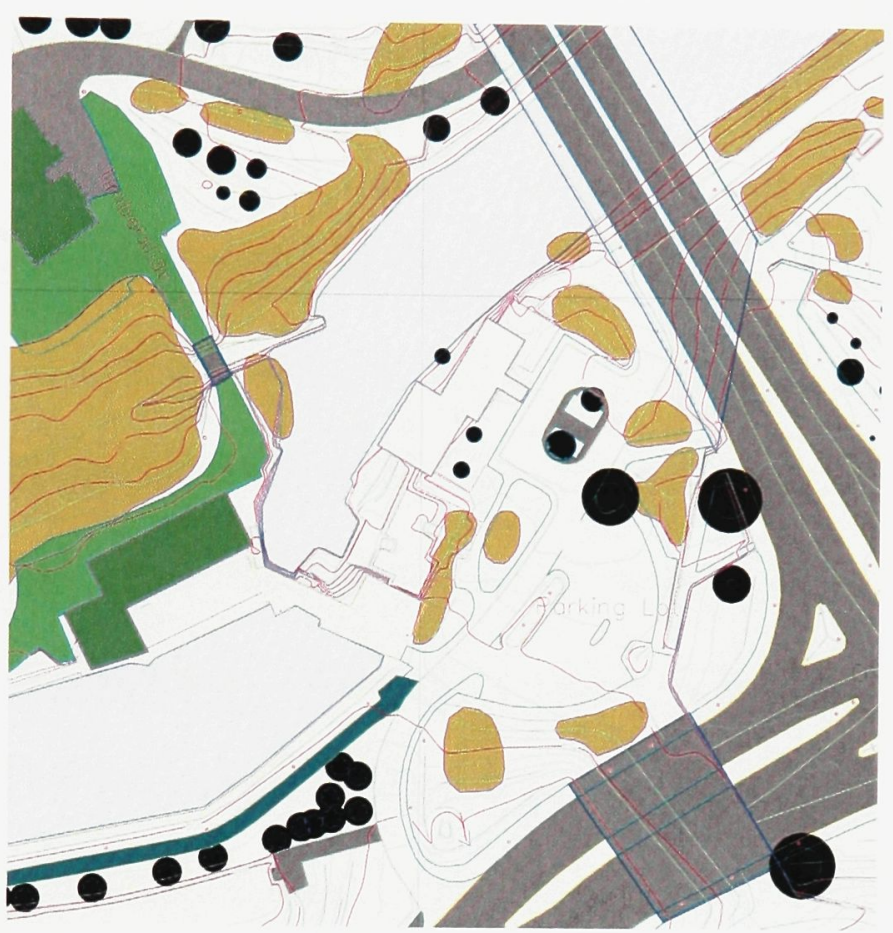

Figure 13. Auto-Cad Plan of the Site Showing the Ottawa River and the Parkway to the South, courtesy of City of Ottawa

The site of the project is located in the north eastern corner of Lebreton Flats,

Ottawa. I chose a site in this area because of the rich historical past, the interventions that happened over time, and the recent developments which will change the city. ${ }^{22}$ The existing site is the result of two opposing, yet strangely complementary movements. The first is the industrial use of the Ottawa River and the construction of buildings that are now recognized the architecture of Canada's industrial heritage. ${ }^{23}$ The second movement is the antithetical yet equally strong movement by the federal and local government to

\footnotetext{
${ }^{22}$ NCC Website, accessed in October 2007,

$<$ http://www.canadascapital.gc.ca/bins/ncc_web_content_page.asp?cid=16300-20444-2050620508 \&lang $=1>$

${ }^{23}$ All about Ottawa, 2007, < http://www.teskey.com/ottawa/ $>$
} 
restore natural scenery to the city. ${ }^{24}$ The waterfront was a special focus as it was to be redesigned into a landscape worthy of the National Capital. Unlike the rest of Lebreton Flats, which was left as snow dump for the last fifty years since the expropriation of the area, this section was almost immediately redeveloped by the NCC into a parking lot serving the river park.

The site runs along an eroded portion of the geological escarpment that runs from the lower portion of Lebreton Flats to beyond Parliament Hill. As the site has undergone years of geological and man-made change, it now sits much closer to the river than the surrounding area. The construction of the Ottawa River Parkway further reinforces a strong vertical separation between the upper plane of the road and lower datum of the central site. The lower datum, now a parking lot, is bounded by the Ottawa parkway to the South and the Ottawa River to the North. During the 1960s the entire site was leveled, compacted, and converted into the parking lot which now serves the entrance the Capital Park and a restaurant, now known as the "Old Mill" took over the main industrial building remaining on the site. The location is also central to the urban circulation through its convergence of roads, waterways, and bicycle paths. Immediately to the east of the site the, portage bridge crosses the Ottawa River over the intermediate Victoria Island.

${ }^{24}$ All about Ottawa, 2007, $<$ http://www.teskey.com/ottawa/> 


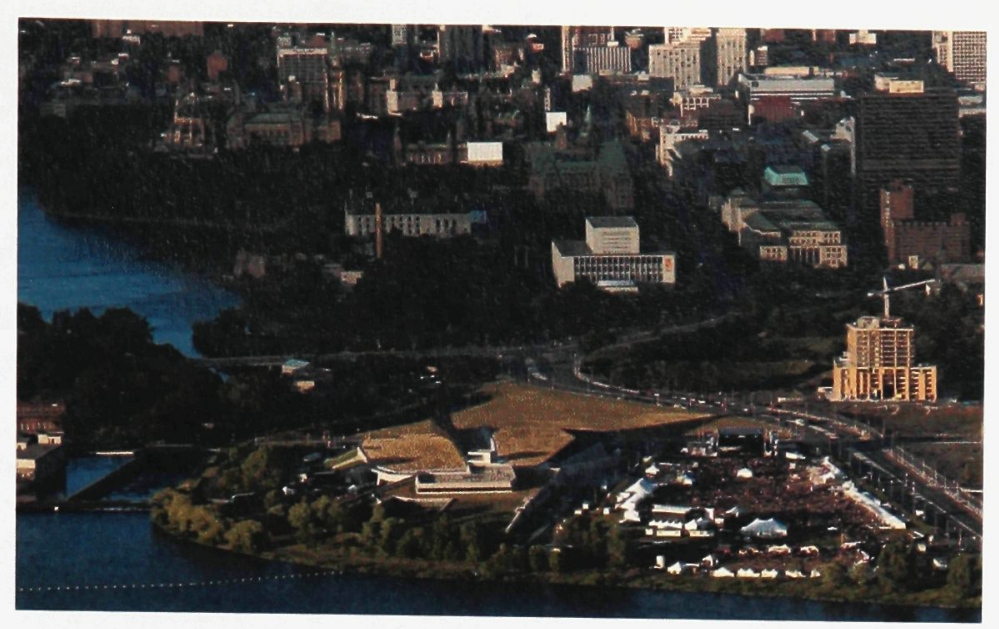

Figure 14- Aerial photograph of the site in context

The Portage Bridge and Wellington Street are both part of the Confederation Boulevard, which was established in 1985 to link the major historical and institutional sites of the region. ${ }^{25}$ The Boulevard extends along both sides of the Ottawa River between the Portage and Alexandra bridges. The site's edge on the river features industrial remnants, the main building is an old grist mill formerly known as the Thompson-Perkins Mill which was restored by the NCC during the 1960's and has since then been operated as a restaurant known as The Old Mill with varying degrees of success. The edges of the site that border the parkway were landscaped during the middle of the last century as two artificial hills. These mounds of earth were planted with seedlings which have since matured into large trees. Although these landscaping interventions soften the edge between the upper and lower datum, the absence of usable surface and the difficulty of walking over them limits their usage and make them primarily a visual item. The parking lot which was built to serve the Old Mill Restaurant and the entrance to the parks was once useful as the location was somewhat removed

\footnotetext{
${ }^{25}$ NCC Website, accessed in October 2007, available at

< www.canadascapital.gc.ca/bins/ncc_web_content_page.asp?cid=16300-20444-20505\&lang=1>
} 
from major populations since the expropriation of Lebreton Flats. Today however, the site is an important location in the middle of Ottawa and links large numbers of the workers, tourists, and future residents of the Lebreton Flats development. Due to these changes, the parking lot no longer fulfills the site's natural calling as a space with a stronger sense of community and greater potential for social interaction.

In Gatineau, the Chaudiere and Portage office complexes share over 70000 government employees residing on both sides of the bridge. The large number of Ontario residents who work in these complexes make their way over the portage and Chaudiere bridges twice a day. On the Ontario side, the lower town and center town business districts provide employment to an even greater number of workers through private businesses and federal offices concentrated along Sparks, Queen, and Albert Streets. The residential areas in center town are home to many government employees who work in the Portage and Chaudiere complexes and therefore also encounter the site daily.

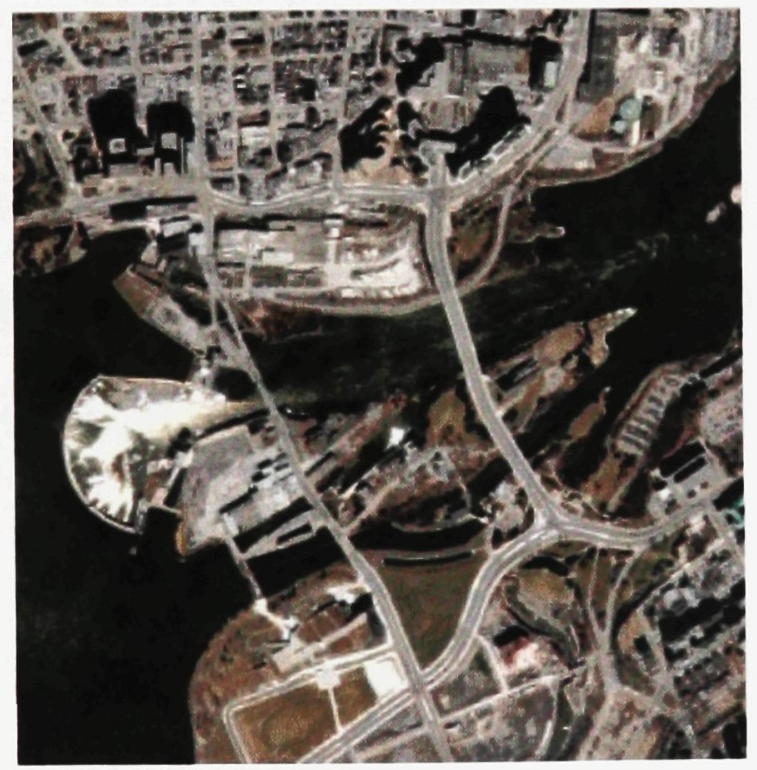

Figure 15-Image of the Site within Confederation Boulevard

With the addition of the new Lebreton Flats residential development, financed by Claridge homes and designed by Hanganu Architects in collaboration with Daoust 
Lestage Architects, the downtown area is extending to the West of Ottawa over Lebreton

Flats. This will lead to an important addition of non motorized traffic that will make its way through the site every day.

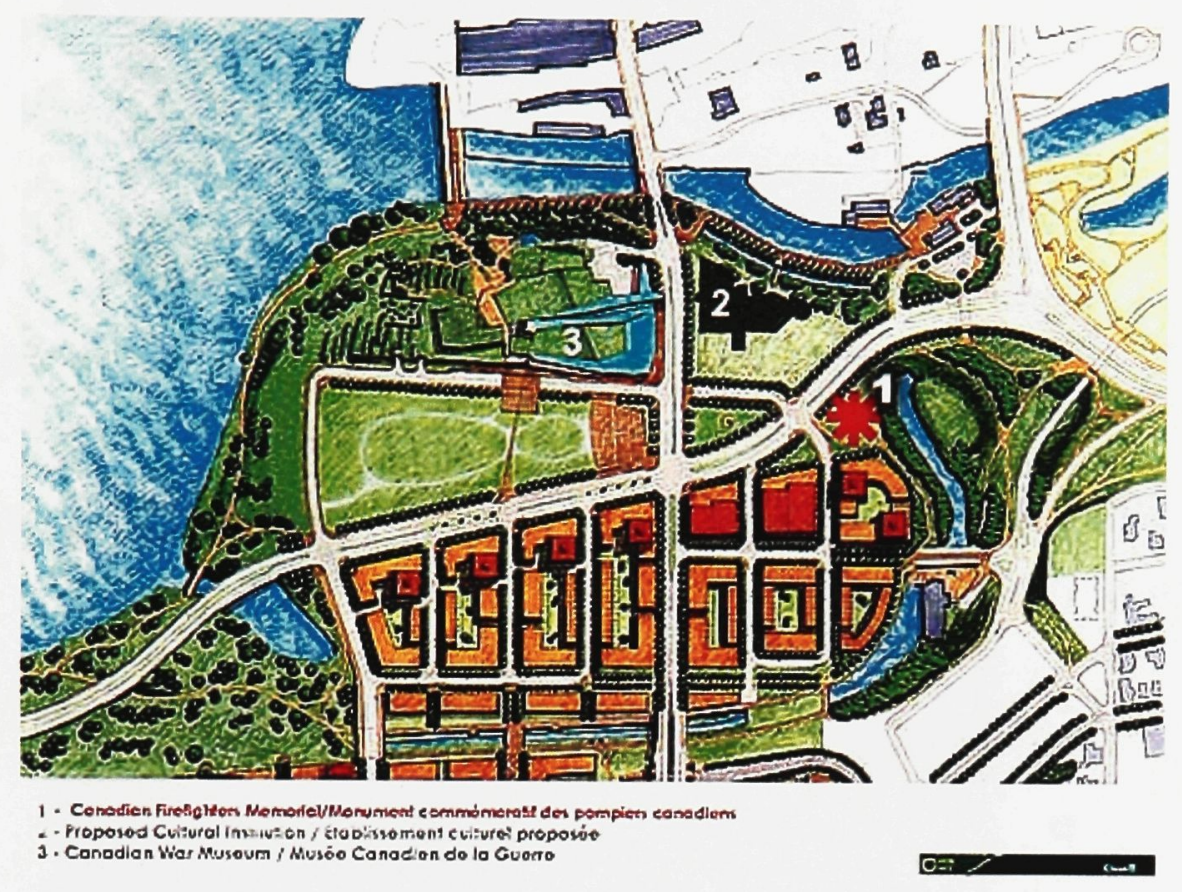

Figure 16-Rendering Showing Future Developments by Claridge Homes. Courtesy of NCC

Currently, the site is linked to the confederation Boulevard by a ramp that descends into the parking lot from the intersection of portage and Wellington. A tunnel passing under the Parkway connects to the southern end of the site where it joins an array of bicycle paths which join on the opposite of the Parkway just beyond a water pumping station. 


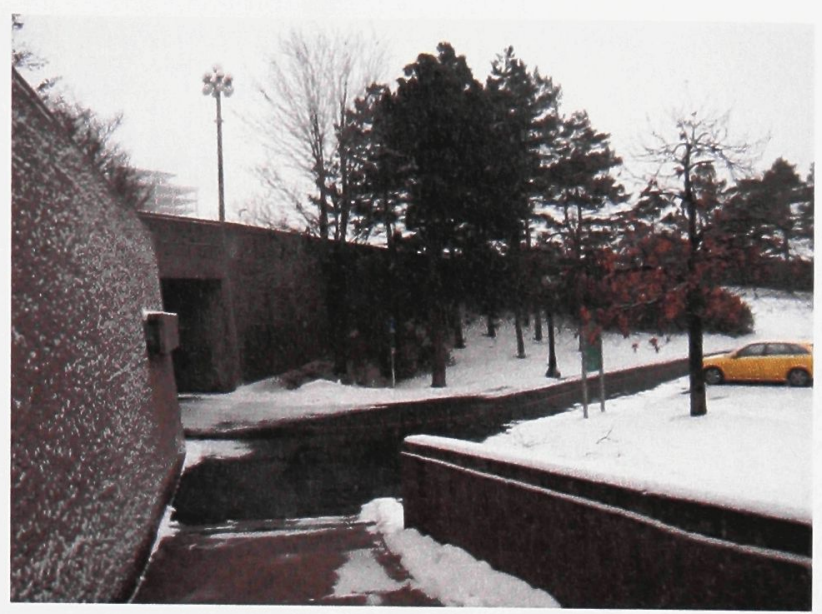

Figure 17- Photograph of the ramp descending from the Parkway into the site

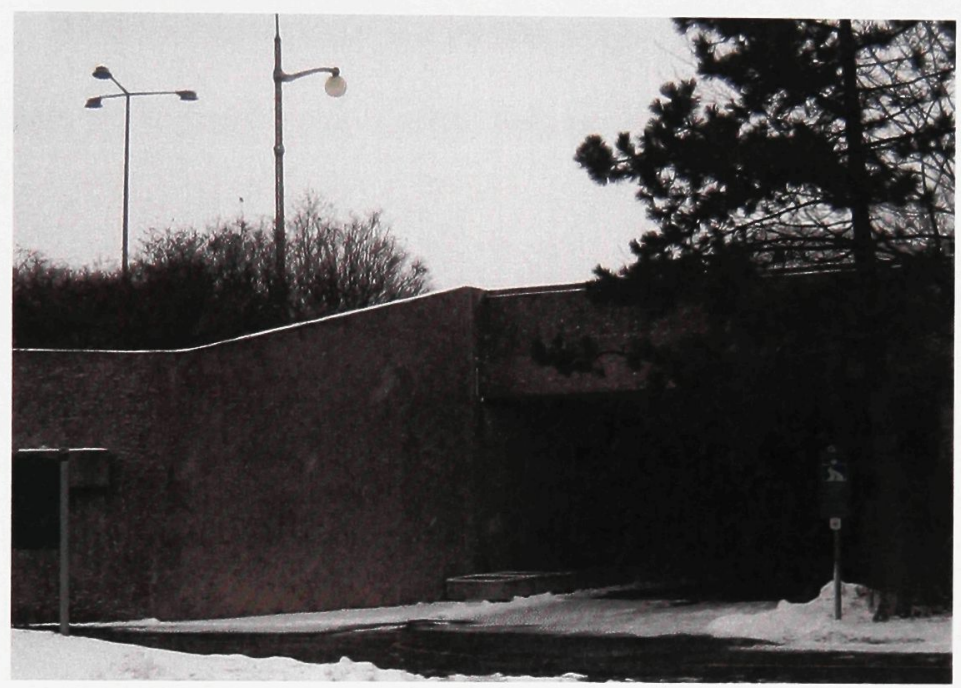

Figure 18-Photograph of the tunnel connecting the site to the bicycle leading to the pumping station and center town

Dams built across the river for a hydro electric facilities offer potential for circulation as adapting these dams to public use would provide a pedestrian bridge to Victoria Island. 


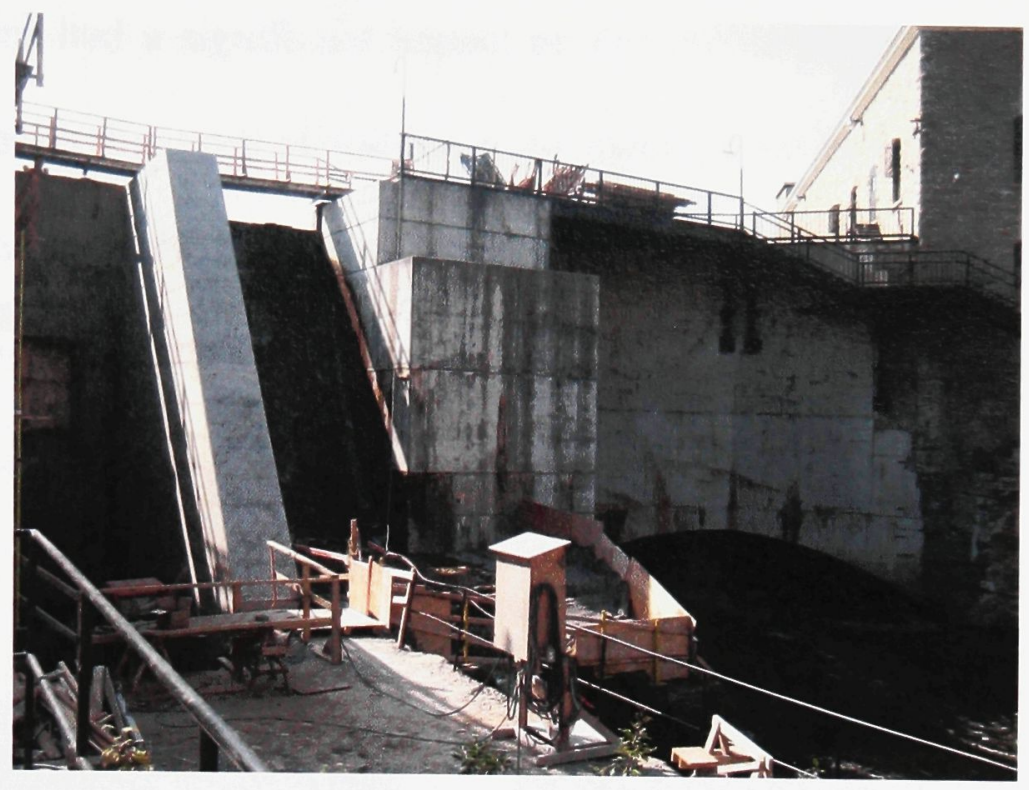

Figure 19-Photograph of the small hydro electric dam and a walkway currently used by employees

This passage using the old dam is especially relevant since future plans have been made to adapt and use the industrial buildings on these islands for commercial and institutional uses and convert these grounds into a vibrant destination filled with restaurants, shops, and cultural institutions dedicated to the aboriginal and industrial history of the islands. ${ }^{26}$ As residents and tourists will likely use the new commercial areas as they pass from one side of the river to the other, the site will become an important part of the overall traffic flow.

I have always been intrigued by structures as the elements that struggle with gravity in order to provide shelter and comfort to the human condition. This fascination with structural expression is what pushed me towards this site. The simplicity and strength of the load bearing walls provide an interesting experience as structure battles the forces of gravity. If one looks back a few centuries, it is easy to see that landscape,

\footnotetext{
${ }^{26}$ Shannon Basset, "Logjammed", Canadian Architect, January 2007. Accessed March, 2008. Available: $<\mathrm{http} / /$ www.canadianarchitect.com/issues/ISarticle.asp?id=183232\&story_id=198722134700\&issue=0101 $2007 \& \mathrm{PC}=\& \mathrm{R}$ Type $=>$
} 
climate, and traditions had a significant impact on the choice of structural systems that were used. This impacts the types of buildings, the dwelling behavior of individuals, and thus of the respective society as a whole since the possibilities for architecture were dependant on the type of system used. ${ }^{27}$
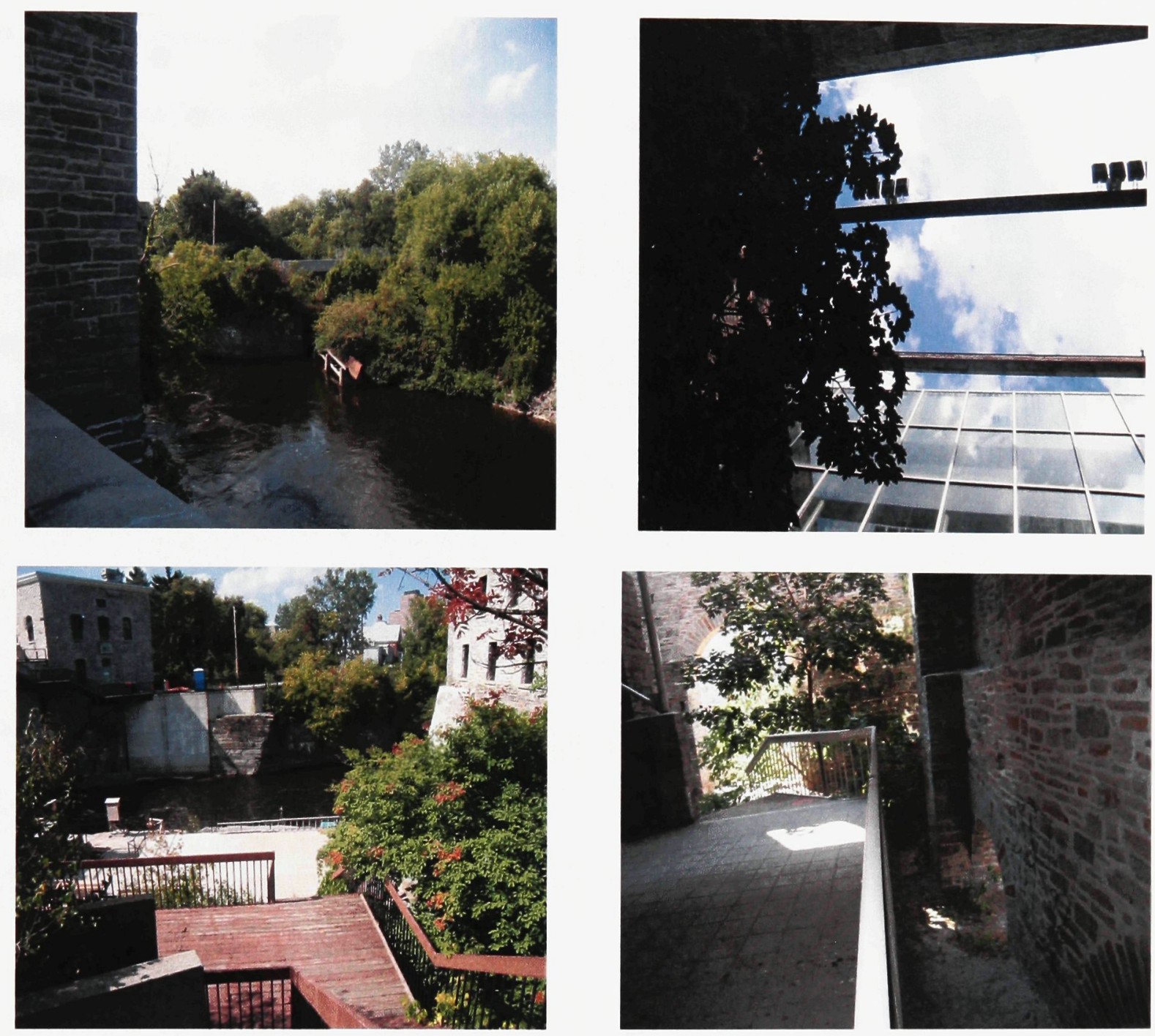

Figure 20- Photograph of the load bearing structure built of locally quarried Nepean Limestone

The site is exemplary of architecture defined by a structural response to landscape as a load bearing masonry building was erected from pieces of limestone carved out of

\footnotetext{
${ }^{27}$ Christian Norberg-Shultz, Architecture: Presence, Language, Place. Milano, Italy: Skira, 2000 p. 28.
} 
the bedrock. The relationship to the site is articulated by the building structure as well as the local flora which as begun grow around and within the walls bringing attention to them as an architectural extension of the cliff. The age of constructing a building exclusively with structural ingredients from the local field may be over and I do not wish to return to nostalgic methods, but I believe this building can serve as inspiration for the future with its dialogue between habitation and landscape through its structural response. The building behaves like a remnant of weathered rock. It extends out of the lower plane of the site and its roof line is at the level of the parkway. The building remains a true structural response to the site, the landscape, and the history which informed the architectural response.

\subsection{Local History}

Lebreton Flats and the surrounding Islands are rightfully starting to be developed, as such central locations deserve attention in the city. However, as these areas make up the capital's most culturally loaded waterfront, care must be taken in order not to destroy all the remaining industrial buildings and the stories they tell. ${ }^{28}$

Prior to the arrival of Europeans during the seventeenth century, the lands now known as Lebreton Flats, Chaudiere and Victoria Island were used primarily by the Algonquin Aboriginal tribe for hunting. Following the arrival of Samuel de Champlain in 1613, the region switched numerous times between French and British occupancy. As time when on, the French colonists settled on the North Shore now know as Gatineau

\footnotetext{
${ }^{28}$ Debanne, Janine. "Flats on the Flats", Canadian Architect, September, 2005, available from:< $\mathrm{http}: / / \mathrm{www}$. canadianarchitect.com/issues/ISarticle.asp?id=167489\&story_id=977201 14749\&issue $=090120$ $05 \& \mathrm{PC}=\& \mathrm{RType}=>$
} 
while the British settled to the South in Ottawa. As the powerful streams of water separating the territories made portages necessary to get up or down stream at this point, a number of temporary resting stations began to emerge on the islands. As the industrial revolution began making its way over to these territories during the early $19^{\text {th }}$ century, the powerful rapids and falls became a source of energy for industrial power and the region began to grow in population. The primary industrial complexes developed around the waterfalls separating Chaudiere Island from the mainland shore of Hull. Notable companies such as the E.B Eddy pulp and paper mill and a number of lumber barons settled in Hull and on the Chaudiere Island while smaller complexes such as the Thomas Wilson Carbide Mill and Thomas Perkins Grist Mill developed on Victoria Island and the eastern edge of Lebreton Flats. As the industry developed around the river, the neighborhoods of Hull and Lebreton Flats became increasingly populated and developed into sizeable communities with hotels, churches, entertainment facilities, and a network of street cars. ${ }^{29}$ Unfortunately, in 1900 a major fire started in Hull and swept over the river to the islands and Lebreton Flats by means of the numerous lumber yards. ${ }^{30}$ As a result of the great fire, most of the homes were destroyed, yet many industrial buildings were left standing due to their heavy masonry structures. Many residential and commercial buildings in Hull and Ottawa were rebuilt in the following years, but due to the speed of reconstruction, the quality of the new construction suffered greatly. As a result, the wealthier families relocated their businesses relocated elsewhere and the

\footnotetext{
${ }^{29}$ Phil Jenkins, "The Enduring Value of Place", An Acre in Time. Toronto: Macfarlane Walter and Ross, 1996. pp 157-185

${ }^{30}$ NCC Website, accessed October 2007,

$<$ http://www.canadascapital.gc.ca/bins/ncc_web_content_page.asp?cid=16300-20444-20506-

20508\&lang $=1 \&$ bhcp $=1>$
} 
surrounding communities became primarily working class. Although the level of culture and finance changed, the communities of Hull and Lebreton developed new businesses and activity slowly returned despite a number of social problems which developed over the years.

The choice of Ottawa as the capital of Canada in 1857 brought many changes to the city's planning and design strategies. In order make the city of Ottawa more worthy of a nation's capital, the federal government opted for the Ottawa Improvement Commission in 1899 whose simple yet imposing mandate was to beautify the industrial city of Ottawa using urban parks, scenic driveways and promenades. In 1959, the Improvements Commission was given a permanent institutional position in the National Capital region as the National Capital Commission. Following the institution of the NCC changes began largely based on a plan which had been developed by the French modernist planner Jacques Greber. Like his modernist contemporaries, Greber believed in a renewed enlightened planning strategy and a severance to what he saw as "uselessness historical ties". ${ }^{31}$ The plan thus called for a complete expropriation and removal of the of the Lebreton Flats community which was to be replaced with the Ottawa River Parkway which now runs across Ottawa from east to west along the river. The plan was finally put in place in 1962 , only two years after the NCC was born, and over 3000 residents of the Lebreton Flats Community were forced to leave their homes as the Ottawa River Parkway was laid out. Across the provincial border in Gatineau, the NCC spared similar working class communities there. The NCC probably did not feel

\footnotetext{
${ }^{31}$ Phil Jenkins, "The Enduring Value of Place", An Acre in Time. Toronto: Macfarlane Walter and Ross, 1996. pp 157-185
} 
that these areas were casting as strong a shadow upon Parliament Hill and thus did not attempt to purchase the land. 


\subsection{CULTURAL AND EVIRONMENTAL BENEFITS}

Realistically, the cutting down of a single mature tree in the city has no real consequence on global warming or oxygen supply. The real tragedy lies in the destruction of a piece of our city that has matured and evolved over decades. This tree is a piece of history and tells part of the city's story. Like the destruction of a heritage building, the loss of this tree means a loss of part of our identity, our culture, and the place we will leave behind for our children and the generations to come. Through the tectonic landscape approach I hope to design an environment more holistically which I believe will result in a healthier approach to our environmental condition, a more practical use of urban space, a more respectful approach to heritage buildings and cultural landscapes and a better terrain for social interaction.

\subsection{Scope of Tectonics in Ottawa's Cultural Landscape}

While architecture of buildings is understood by many professionals and laymen as a combination of structural elements that provide shelter to human beings, landscapes are often conceived in a picturesque way that simulates nostalgic images of pre-industrial conditions of nature. However, architecture is built not only to provide shelter, but also comfort, mental wellness, and a healthy long term sustained interaction between humans and their environment. Therefore, buildings and outdoor constructed landscapes can be understood equally as architecture in order to provide optimal conditions for humans and their living environment. ${ }^{32}$

The Etymology of Tectonics derives rom the Greek word "Tekton" which is

\footnotetext{
${ }^{32}$ Charles Waldheim, "Landscape as Urbanism", The Landscape Urbanism Reader. New York: Princeton Architectural Press, 2006 p. 37
} 
translated as craftsmanship and refers to the actions and objects made by a carpenter, mason, or other type of builder. Today, the definition of "tectonics" refers to the meaning developed by Gottfried Semper. In his study of the elements of a primordial dwelling, Semper spoke of the earthworks, the frameworks, the hearth, and the enclosing membrane. Of these four elements, the earthworks and frameworks were said to be tectonic. Although they are not necessarily part of an enclosure, landscape interventions can be important earthwork interventions and can thus be considered as a part of tectonic culture. The traces left upon the site by the industrial interventions are earthworks through the heavy cuts and displacements of soil and stone. The interventions made by the NCC are also primarily earthworks as the roads, bicycle paths, and bulldozed parking lot are also heavy interventions upon the site. An interesting framework ${ }^{33}$ intervention was also made by the NCC during their restoration of the Mill Building for restaurant use. A light steel structure uses the stone walls of the turbine room as cliff to cantilever over the water and was used by the restaurant as a scenic dining lounge.

\footnotetext{
${ }^{33}$ Gottfried Semper, Tectonics, Style in the Technical and Practical Arts. Los Angeles: Getty Research Institute, 2004, pp. 623-624
} 


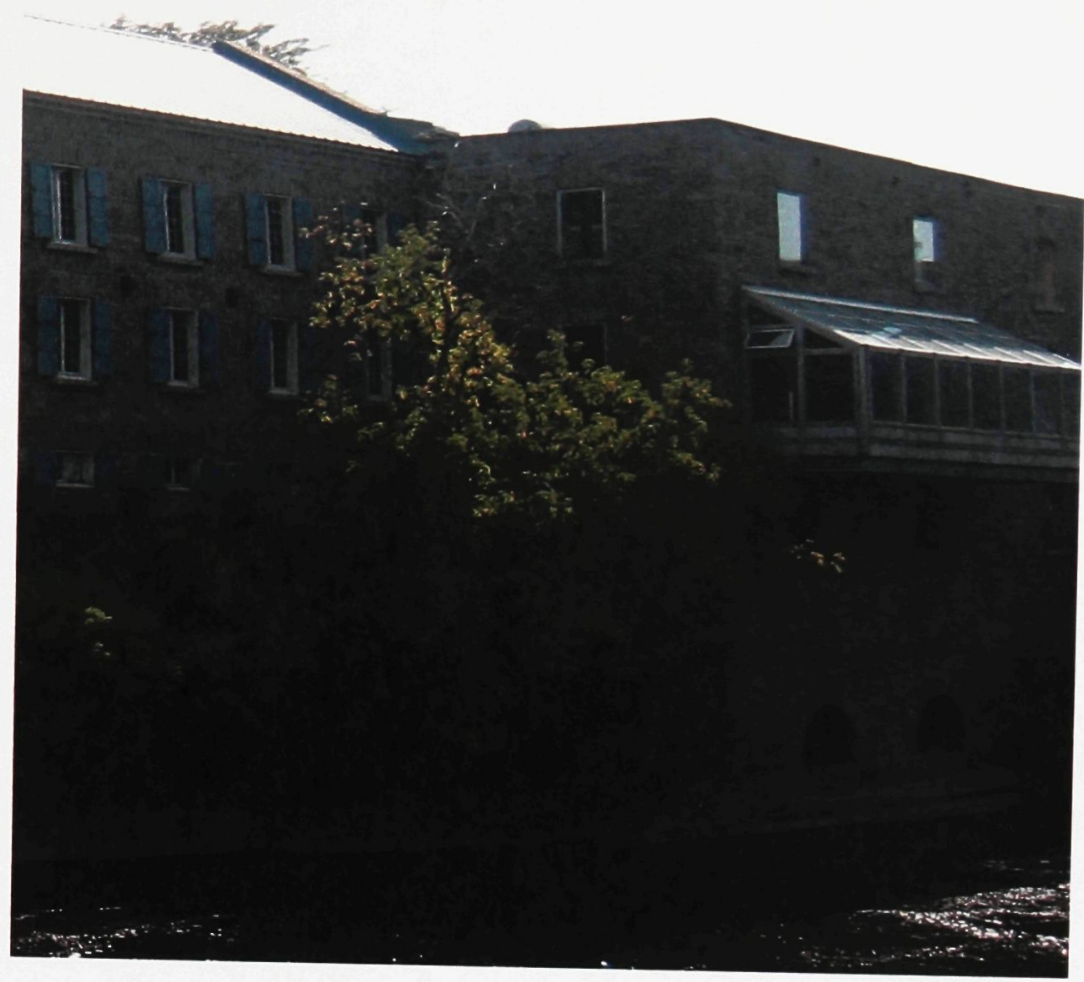

Figure 21-Steel framework structure cantilevers over the river using the stone walls as a cliff

While separating landscape from the conceptual phases of architecture leads to the omission of organic elements in buildings, removing the aspect of tectonic construction in landscape can lead to designs with a lack of rigor and superficial imagery. As a result, the design of impractical landscapes can lack urban integration and cultural relevance to their context. ${ }^{34}$

\subsection{Towards Environmental Sensitivity}

In response to growing environmental problems, stewardship is important to consider in any architecture or landscape design project. Therefore, I will orient the tectonic landscape approach towards that renewal of used space, reuse of architectural fragments, and reduction of construction material consumption. Through its clear

\footnotetext{
${ }^{34}$ James Corner, "Terra Flexus”, The Landscape Urbanism Reader, New York: Princeton Architectural Press, 2006. pp.23-24
} 
articulation of the urban landscapes as constructed architectural environments, the tectonic landscape approach will remain distinct in appearance from natural reserves and thus make its own distinct contribution to deal with the environmental crisis. As we live in an age where the pristine, untouched wilderness we once knew as nature no longer exists without human care, it is necessary that we re-address what we consider progressive development. It is of utmost importance that we stop pretending to be colonists building on a site for the first time and realize that we live in an age of constant renovation, rehabilitation, and renewal. ${ }^{35}$ This objective will be achieved through the reuse of the site's industrial buildings and dams as well as an adaptation of the later changes made by the NCC. The new landscape will speak clearly of the historical weight of the industrial settlements and the capital improvements commission which are now an important part of the city's history. The way to future progress is through an understanding of their tensions and contradictions.

While the tectonic landscapes may use organic elements as part of its construction, it is not to be confused with planned territories of conservation. The confusing aspect of some of the urban parks of Ottawa is that they lie in regions that are relatively undeveloped and the absence of a clear contrast easily confuses man-made landscapes with the wildlife reserves that they border. The sites along the Ottawa River were redesigned for pastoral views of the waterfront after the initial deforestation that took place during the late nineteenth and early twentieth centuries. They were recreated this way in order to appear more natural to the city's riverside parks and to set pastoral

\footnotetext{
${ }^{35}$ James Corner, "Terra Flexus”, The Landscape Urbanism Reader, New York: Princeton Architectural Press, 2006. pp.23-24
} 
scenery for the parliament buildings. The pastoral landscape mediations were planned architectural moves made to embellish the city of Ottawa as a city representative of Canada's ideal for natural embrace. Although of natural appearance, these landscape renovations have a result very different from the one which would have arisen if the industrial remnants were left to "nature" to simply deteriorate and weather as native growth overtakes the old ruins.

In the twenty-first century land has become so rare and urban living so dense that urban landscapes must contribute to the programmatic needs of the city. Contemplative spaces must simultaneously serve utilitarian purposes and respond to the city's demands, maximizing efficiency and minimizing wasted space. Alexander Wilson's "The Culture of Nature" presents a convincing discourse on the need to rethink the significance of landscape and the relationship it bears with the natural order as well as the city, which includes reserves such as the Gatineau Park and its interaction with the City of Ottawa. Though outdoor spaces such as this one present an opportunity to experience nature through the outdoors, the very notion of "dialogue with nature" must be redefined in this context. Sites such as this one present not an escape from city life to the bush, but rather an ongoing dialogue between mankind and organic life through architecture, culture, and history.

In a world where nature, as once understood, has become a pleasant fiction, and wild-life reserves can no longer survive without being cared for, it is essential for humans to realize that their roles have changed from being colonizers of the wild to grounds keepers of a sustainable world. It is for this reason that the remnants of the industrial buildings are important: to recall the beliefs, values, and errors of a different time. At the 
time of construction the industrial buildings and dams, the industrial revolutionists felt a need to control and exploit a brave world and use its powers and resources to the advantage of humanity. The later movement $\mathrm{s}$ by the NCC felt that natural settings needed to be recreated for their beauty as well as their representation Canadian National Identity.

Wildlife reserves such as the Gatineau Park are not wild outback, but planned as territory and extensions of the city, in which the rest of organic life may exercise its right to live. The need for such territories goes far beyond our desire for a walk in the woods or even our need of fresh air, but for the very survival of our species and our way of life. The preservation of animals and plants is essential for preserving our culture and identity as Canadians and foremost as human beings.

Nature is a part of culture. When our physical surroundings are sold to us as "natural" (like the travel ad for a "Super, Natural, British Columbia") we should pay close attention. Our experience of the natural world - whether touring the Canadian Rockies, watching an animal show on television, or working in our own gardens - is always mediated. It was always shaped by the rhetorical constructs like photography, industry, advertising and aesthetics, as well as by institutions like religion, tourism, and advertising. ${ }^{36}$

Wilson believes that movies, cartoons, and documentaries about animals are less a realistic representation of their conditions today than they are a reflection of human nature, a reflection of oneself through the natural world. He further argues that the current

\footnotetext{
${ }^{36}$ Alexander Wilson, "View From the Road: Recreation and Tourism". The Culture of Nature, Toronto: Between the Lines, 1991. p 12
} 
environmental crisis is due to a selfish and confused notion between natural order and natural resource. Such a misguided notion can lead one to believe that territories such as the Gatineau Park may be exploited when the need for wood and other forestry resources exceeds the need for outdoor recreation. In much of human civilization, large amounts of cultural progress were made through the study and analysis of organic life. From the direct interaction of man and his garden to the abstracted motifs of Roman temples to the modern conception of organic architecture, flora and fauna have been driving forces of cultural evolution. Therefore, misinterpretation of the word nature as natural resource is leading to a crisis not only in the environment, but in economies, households, and many realms of our culture. As part of the urban collage, trees and flowers in this tectonic landscape are important for their practical advantages as well by acting as a representation of the importance of organic life in the culture of a city. In a way, these representations of nature are to act like the carved leafs in an ancient Greek temple's column head, as a reminder of a greater inspiration.

Landscape does not refer to a territory or even to a type of scenery, but rather to an idea, an understanding of our place in the world and of our relationship to the natural order.

In the broadest sense of the term, landscape is a way of seeing the world and imagining our relationship to nature. It is something we think, do, and make as a social collective. ${ }^{37}$

Because there is little or no unspoiled natural land left, it is irrelevant to pretend

\footnotetext{
${ }^{37}$ Alexander Wilson, "View from the Road: Recreation and Tourism" The Culture of Nature, Toronto: Between the Lines, 1991. p 14
} 
otherwise through pastoral sceneries denying the situation. In fact, it would be an irresponsible undertaking since it would only reinforce the unrealistic nostalgia that people have toward an uncontrolled green world where wild beasts roam and wilderness is a powerful force that must be tamed in order to make room for civilization. However, when the National Capital Commission made their seemingly natural interventions on the sites along the river such as the one in question, they made them as a response of purification to what they saw as the irresponsible invasion of the natural habitat by lumber and paper barons. To give them some credit however, the most important buildings of the industrial age were left standing. By completely erasing all traces of the past, planting a virtual wilderness and reintroducing program space into it by cutting away a few trees, one neglects the fact that untouched nature has long ceased to exist on the site. Therefore, I insist that remains of the lost buildings as well as parts of the 1960's landscaping be used in programmatic aspects of the design and that these remains be rehabilitated and redesigned to fit the needs of today. Replacing one history by another is no more effective in achieving true progress than conquests of new development over the last undeveloped parcels of land. Instead, true sustainable development is achieved through a sensitive rehabilitation of areas through consolidation and selective preservation. We should maximize the efficiency of the spaces we already occupy and revisit their composition when they are no longer positively contributing to the city.

In order to arrive at the desired results, this project will draw upon three theoretical frameworks: western theories of tectonics of structure and architecture, the idea of the city as a collage of fragments and memories, and the approach to landscape that defines nature as a part of human culture. The need for cultural landscapes is great, 
for as Wilson explains in his book, the environmental crisis we are experiencing today is also a cultural one.

In order for people to reevaluate their relationship to nature, it is essential that the new landscape presents a clear visualization between the relationship of humans with the organic world rather than a territory shaped by non-human forces.

Restoring landscape is not about preserving lands - saving what is left as it is often put. Restoration recognizes that once lands have been "disturbed" worked, lived on, meddled with, developed, they requires human intervention and care. $^{38}$

My hope is that the new design can help more people realize that wildlife as it once was on this site no longer exists, and that we must find a new way of coexisting with remaining life forms in order for either to survive. This understanding of organic life and the relationship it bears to us is crucial to our own existence and survival, and this understanding can hopefully continue to prevail into the future.

With respect to landscape, the task of building a new world (or rediscovering an old one) in harmony with the other species of this earth must begin with understanding the process of contemporary land development and the changes it has brought this continent and our experience of it. ${ }^{39}$

One of the many things we can learn from the natural world is that evolution, much like our own civilization, is an ongoing process, not a periodical replacement of one reality by another. The continuous growth of new trees from the decay of old ones, and the

\footnotetext{
${ }^{38}$ Alexander Wilson, "View from the Road: Recreation and Tourism" The Culture of Nature, Toronto: Between the Lines, 1991. p 17

${ }^{39}$ Alexander Wilson, "View from the Road: Recreation and Tourism" The Culture of Nature, Toronto: Between the Lines, 1991. p 16
} 
recycling of organic matter is a process we can learn from in order to reflect on our history and keep in touch with our culture. Thus, the new landscape shall make clear in all its different elements that organic and man-made creations alike are constantly under change and renewal. The functional areas of the program such as the train station always stay flexible and ready to adapt to new technological innovations. Furthermore, as populations keep growing and the need for clean air intensifies, people should learn to appreciate the dialogue that exists between vegetation and humans. Canada has no more exclusive rights to "nature and the great outdoors" than any other country. The people of Ottawa must change their understanding of the park, of "living close to the forest", to a new vision of park which consists primarily of its ability to allow peaceful coexistence and mutual benefits for urban lifestyle and organic life.

If it is important for citizens to reevaluate their understanding of parks, then it is imperative for tourists reinterpret the meaning of "nature tourism".

The modern history of nature tourism is a history of altered land forums and changed ideas and experiences of the non human. Broadly speaking, it involves a shift from a pastoral approach to a more consumer approach. ${ }^{40}$

It is essential to redefine the notion of "nature tourism" as the interaction between mankind and the organic world rather than as admiration of a sublime natural land. This landscape, like any other urban park should be treated not as a small forest that decongests the city, but as an active part of the city itself.

Since at least the witch burnings of the sixteenth century, people of European

\footnotetext{
${ }^{40}$ Alexander Wilson, "View from the Road: Recreation and Tourism" The Culture of Nature, Toronto: Between the Lines, 1991. p 24
} 
origin have regarded nature as separate from human civilization, which makes it possible to argue for its protection. The Native people of North America have never shared this attitude. For them the natural world is not a refuge - but a place that is sacred in and of itself. In native Cosmologies, human cultures are compatible with natural systems, and it is human responsibility to keep things that way. ${ }^{41}$

With "nature" surviving only in our protective hands, it is imperative that we start learn how to allow organic life to thrive while enhancing our everyday life. Architects, citizens and city planners can learn to use landscape the same way as traditional architecture, for spaces dedicated to every day activities. Tourists will hopefully appreciate this landscape for its relation to people and their culture as much as for the intrinsic beauty of trees and flowers.

The new landscape calls for the end of developmental colonization and for the start of a new era of urban renewal. With urban living being so dense, landscape designers should consider the programmatic needs of the city, using plants like trees and grass to fulfill the program. The project shall encourage non-motorized transportation, cultural exchange and recognize natural surroundings as part of a city's culture. The new landscape will become a collage of different eras in the city's history with architectural remnants of the industrial age, the pastoral landscape age, and the beginning of today's age that proposes a renewed approach to landscape and sustainable development.

\footnotetext{
${ }^{41}$ Alexander Wilson, "View from the Road: Recreation and Tourism" The Culture of Nature, Toronto: Between the Lines, 1991. p 25
} 


\subsection{Traces and Memories in the Urban Landscape}

Because the interventions made by the NCC during the last century are easily confused with a natural landscape, certain people such as members of the NCC Watch $^{42}$ see their actions as irresponsible and as a destruction of precious history. However, from a historical perspective, it is easy to see the situation differently. The implementation of bicycle paths, roadways, and parks may have erased certain traces of the industrial history, yet these actions are part of a historical movement themselves and have added a new layer interest to the site. The moves that were made by the NCC during the early 1960 's were not the destruction of a history, but also the creation of a new one. They are a new set of architectural insertions using a different set of materials and methods. Today, we are faced with a new and unique situation and an interesting challenge in understanding the tensions and oppositions between these two sets of interventions in the cultural landscape and allowing them to work together without losing their individual strength and conviction.

In the article "Plotting Traces on Process"43 Stan Allen mentions Aristippus' overjoyed feeling as he finds traces in the sand of a deserted island to which he was cast ashore following a shipwreck. These abstract traces symbolize human presence, and thus hope since he is not alone. The shipwrecked philosopher referred to the marks he saw as "Vestigia" which also imply footprints, signs, traces, or ruins pointing toward the past. Similarly, in architecture and landscape, clues of the creators remain. Inspirations, processes, methods, are left behind in the form of traces through the various steps of the

\footnotetext{
${ }^{42}$ NCC Watch Website, accessed March 2008, < http://www.nccwatch.org/features/timeline.htm>

${ }^{43}$ Stan Allen, "Plotting Traces of Architecture". Practice, Architecture Technique and Representation, New York: Taylor \& Francis, 2000
} 
conception, representation and realization. Just as in the case of the lost explorers, architectural processes leave signs binding the built environment to their creators. The city as a region's collection of architectural fragments over a period of time becomes a collage of positive and negative traces left in the tectonic landscape.

Indexical signs are bound to their referent through some form of contact, physical or otherwise: An index is a sign which refers to the object that it denotes by virtue of being really affected by that object. ${ }^{44}$

Traces exist in one of two forms following their respective design process. The first are positive traces which are the result of design through a gradual elaboration of a basic idea. The second are negative traces, left due to erasing as part of editing or as source for a positive trace.

The new tectonic landscape is in itself based on a number of physical traces and fragments of Ottawa's industrial and institutional history on the site which are put together as a complete picture in response to its current urban context. Like the urban collage made up of a number attempts to rationalize the city, the design proposes an organizational planning based on the existing interaction of fragments instead of a purist abstraction. The design is presented in the next section and will address the issues discussed in this section. Tectonic culture and craft in landscape architecture, environmental stewardship, and urban memory will be addressed by making specific moves in the design.

\footnotetext{
44 Stan Allen, "Plotting Traces of Architecture". Practice, Architecture Technique and Representation, New York: Taylor \& Francis, 2000
} 


\subsection{FINAL DESIGN}

To generate architecture more connected to the Ottawa region, where single histories are not as rich as in older cities, I used a design logic based on a collage of the prominent historical movements and cultural interventions in the city. The design of this new urban landscape owes its conception primarily to the industrial interventions on the Ottawa River and the NCC's movement of recreating a pastoral waterfront. The genius loci based on this collage of historical approaches of architecture and landscape is further developed through its adaptation to Lebreton Flats as a westward extension of the downtown core. Due to current developments, the site becomes increasingly important in the city as an urban park, a node of for non-motorized circulation, and a social hub. As an urban park, the site offers a moment of tranquility and reflection within the city as well as connection to outdoor activities along the river. Because of its central location between downtown Ottawa and Gatineau, the site become an intersection for people traveling by foot or bicycle between home and work as part of their everyday routine.

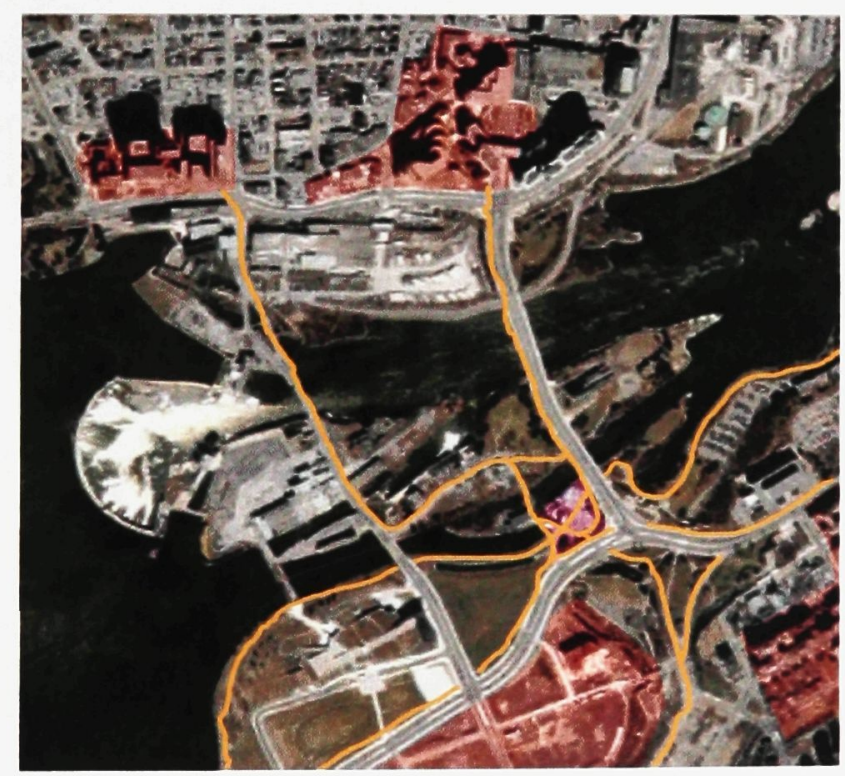

Figure 22-Non Motorized Urban Circulation and convergence at the site 
Because of its linkage to new the local community, urban centers, (Ottawa and Gatineau) and tourist destinations such as the riverfront, museums, and parliament, the site will likely become a public axis. As a new downtown public space, the new landscape and its buildings will serve the different groups of people that regularly make use of them. The design will engage its users coming from different social groups and favor their interaction through public performances, sports, and socialization. Three important groups of potential users are local community residents, citizens working in proximity, and visitors of the city.
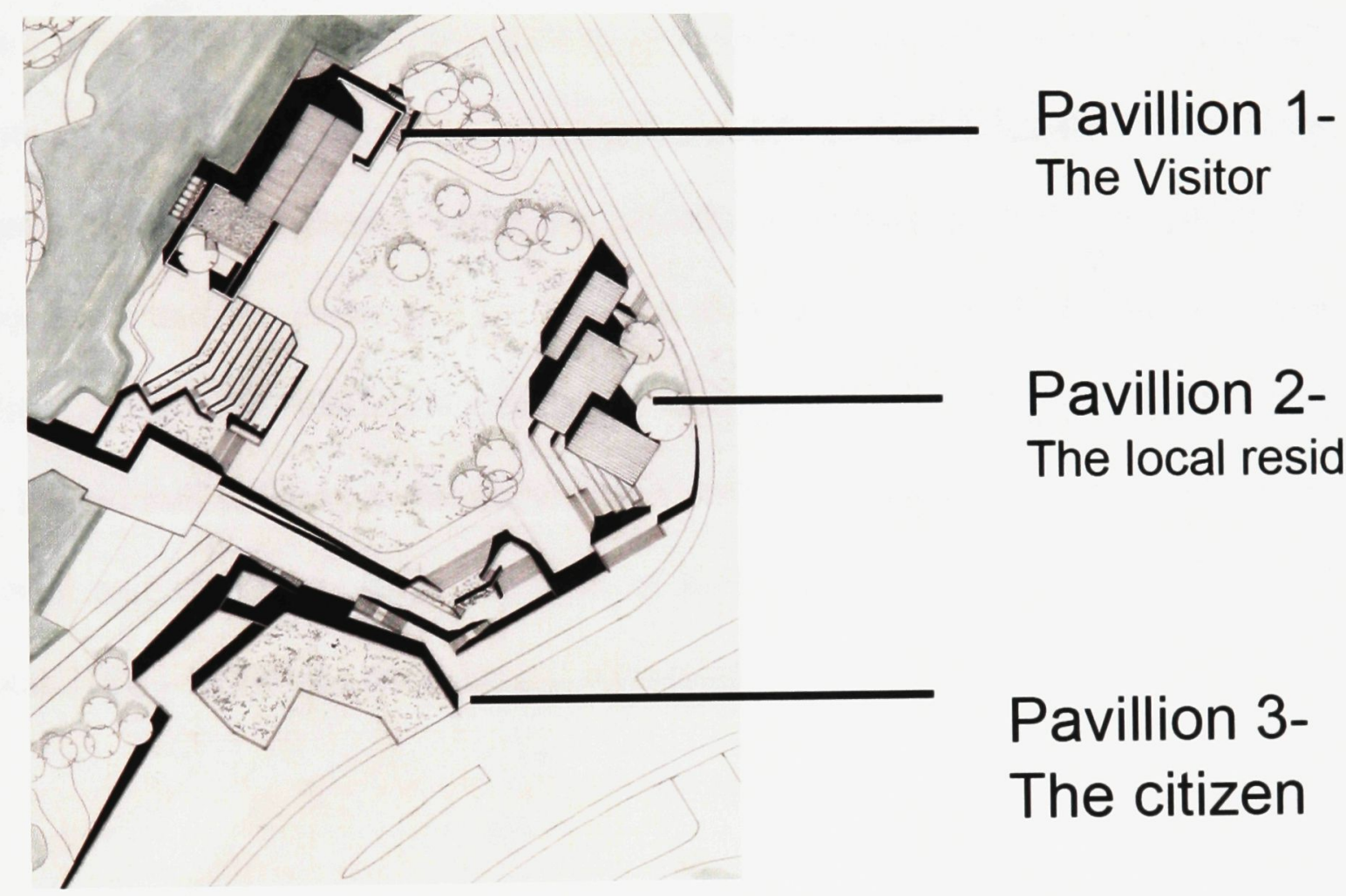

Pavillion 2The local resident

Figure 23- Site Plan with Annotated building Pavilions

All three buildings will be shared by the different groups in slightly different proportions. Pavilion 1, the Old Mill, will be used primarily as a visitor center offering a refreshment counter, dining terrace, exposition center, and rental shop for bicycles and roller skates. Pavilion 2, facing the Old Mill, will be used primarily by local residents as 
a center for meetings and community events. Pavilion 3, adjacent to the dam will sport a waterfront restaurant, a library, and a small theater for all citizens and visitors. All three buildings have two entrances, one to Road and Parking, the other to the inner court reserved to pedestrians and cyclists.

By visiting and reading about historical cities, I have come to the realization that one of the characteristics common to most successful piazzas, urban parks and squares is the theatrical quality that extends over the entire space. This characteristic tends to make a place livelier as it draws people who come to interact, observe, and be observed. It also makes a safer place as an overall visibility reduces the chances of crime and mischief. The site's combination of historical constructs provides an ideal framework for a layout analogous to an urban theater within the amphitheater-shape geometry formed by the Ottawa River and the Parkway. On the land sloping inward from the parkway, new pavilions and outdoor platforms will act as viewing terraces, the central court as the stage, the old mill building as the stage setting, and the bicycle paths as the passageways for actors and spectators, while the view of the Ottawa River, Downtown Hull, and Gatineau Hills will provide the theatrical scenery and backdrop. 


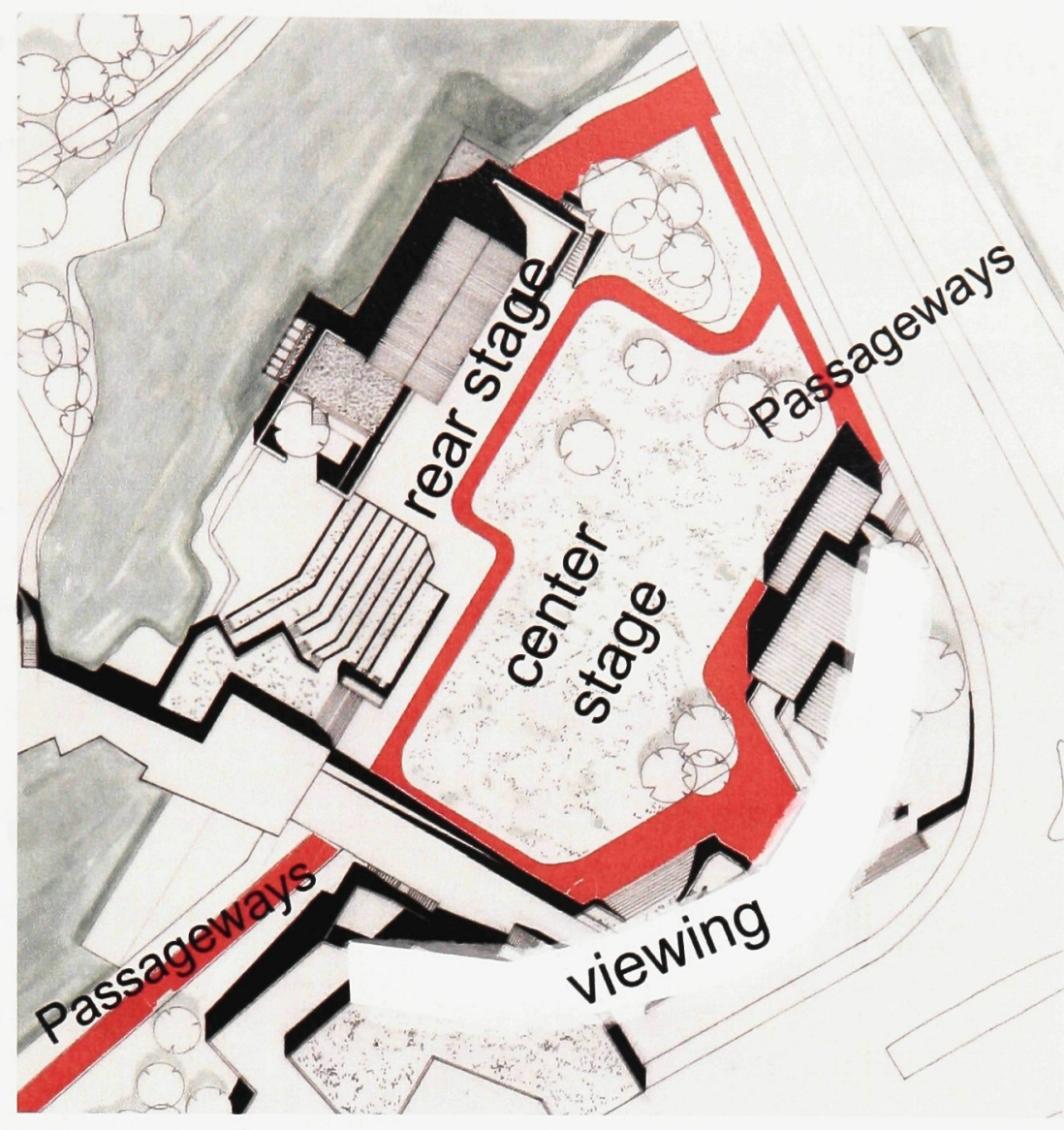

Figure 24- Annotated site plan and model showing the use of the site as a public theater defined by the Parkway and Ottawa River

In the new landscape, the stage is the central court. It is a grazed field grown what used to be a parking lot for entrance to the Ottawa River Park and the Old Mill Restaurant. Although not evident at first sight, the central court directly uses the former parking lot as precedent since the space has been cleared of obstructions and ground is already compacted to hard earth. The new space shall set a stage for cultural exchange, special events, and sports in every day life. In the summer, the inner court provides an ideal spot for children to play while grownups sit down, relax, and get a tan. For special occasions such as Canada Day or the Tulip Festival, the space can be used as an orchestra for outdoor concerts, shows, and other types of outdoor events. In the winter, the inner court maintains is place for performance as the flat surface is of ideal 
dimensions to be converted into an outdoor hockey rink. Friends and Family of the players can comfortably watch their children play from pavilion 2 as the building has indoor terraces with large windows ideal for watching. The ice rink can also be used during Winterlude for skating performances or recreational skating around ice sculptures.

The mounds of earth facing inward from the parkway will be carved to provide space as terraces for outdoor rest and seating. Two new buildings, pavilions 2 and 3, will also be part of the viewing area as they face inwards viewing the central court. The materials and construction of the elements making up the buildings and terraces will refer to the history of the site and the city of Ottawa. Both buildings are a continuation of the man mediated topography of the site along the river.

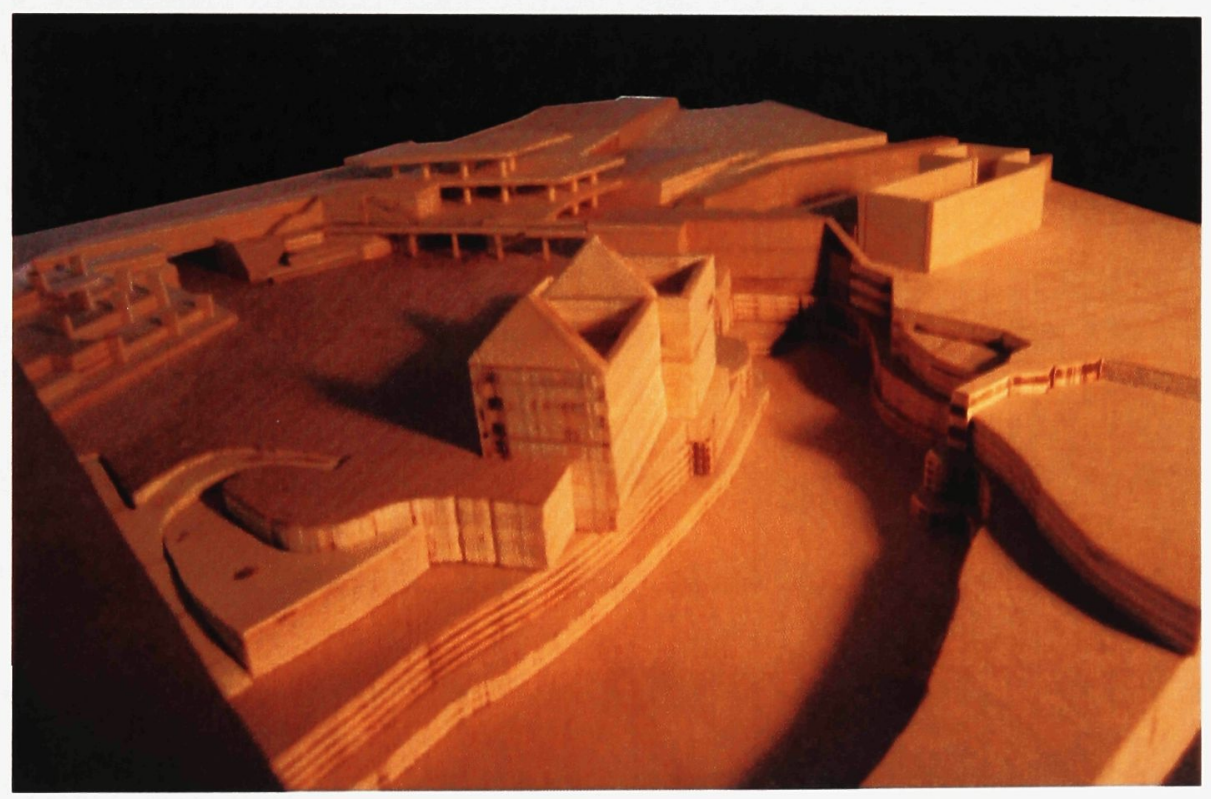

Figure 25-Model Photograph showing the topographical form of the buildings and outdoor platforms of the viewing area 


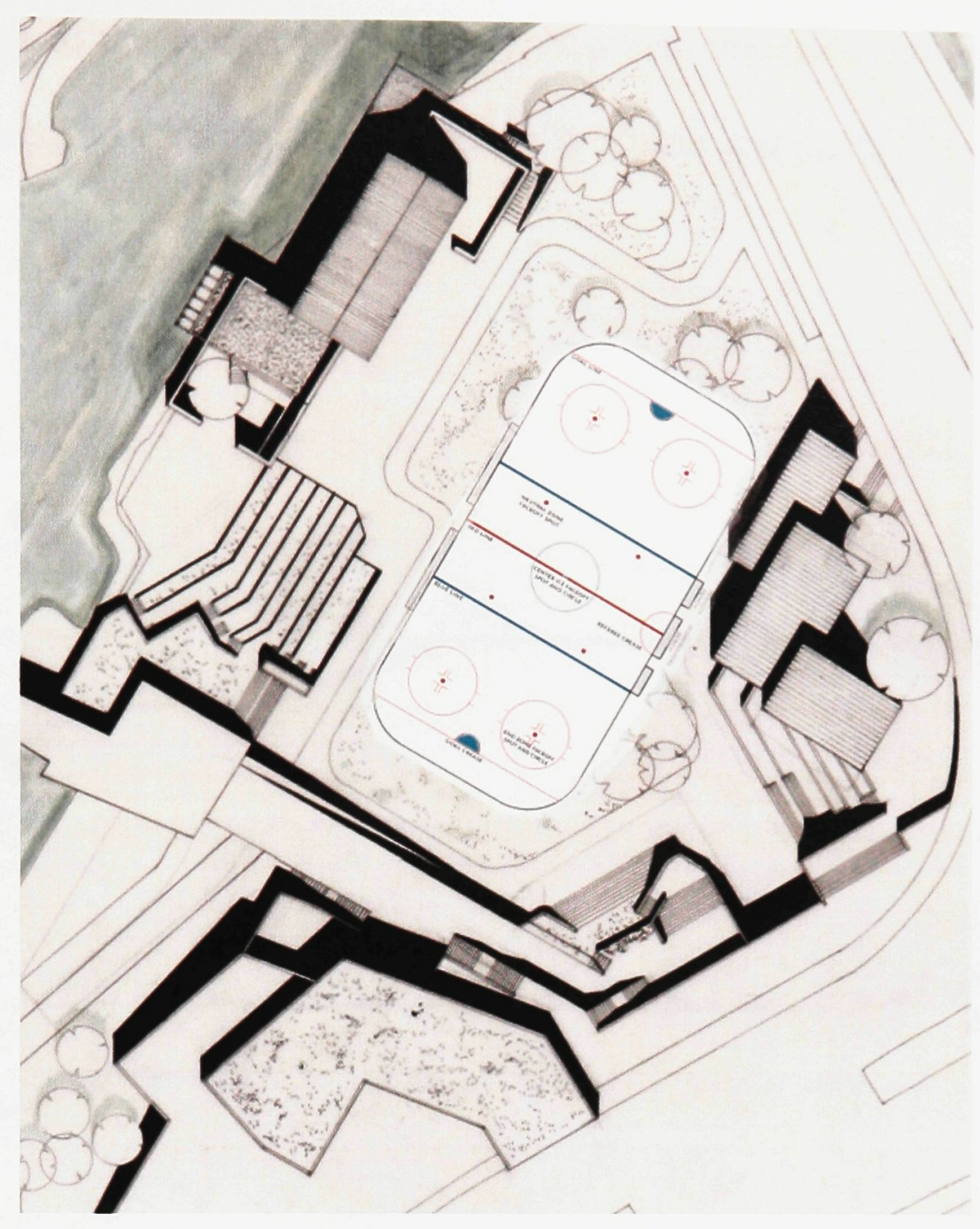

Figure 26- Ice Hockey rink in the central court during winter $(61 \mathrm{~m}$ X 26m, NHL standard dimensions)

Pavilion 1 continues the earthwork of the site by carving into the existing mounds of earth and pouring of the retaining walls not unlike the dams by the river. The building can be shared by all users, but is most useful to local residents for community meetings, cultural activities, and events. This pavilion feels the earthworks of the terrain flow underneath it, becoming the floor while the inter-level retaining walls rise to a height of 2 meters where they support steel columns mounted by a space-frame truss. Much like the old mill, this building's primary structure is composed of a heavy earthwork intervention and a light framework mounted on top. The pavilion also becomes an 
accompaniment to the person's body descending into the landscape as he is juggled between the weight of his feet on the earthwork's mass and his visual contact with the sky. ${ }^{45}$
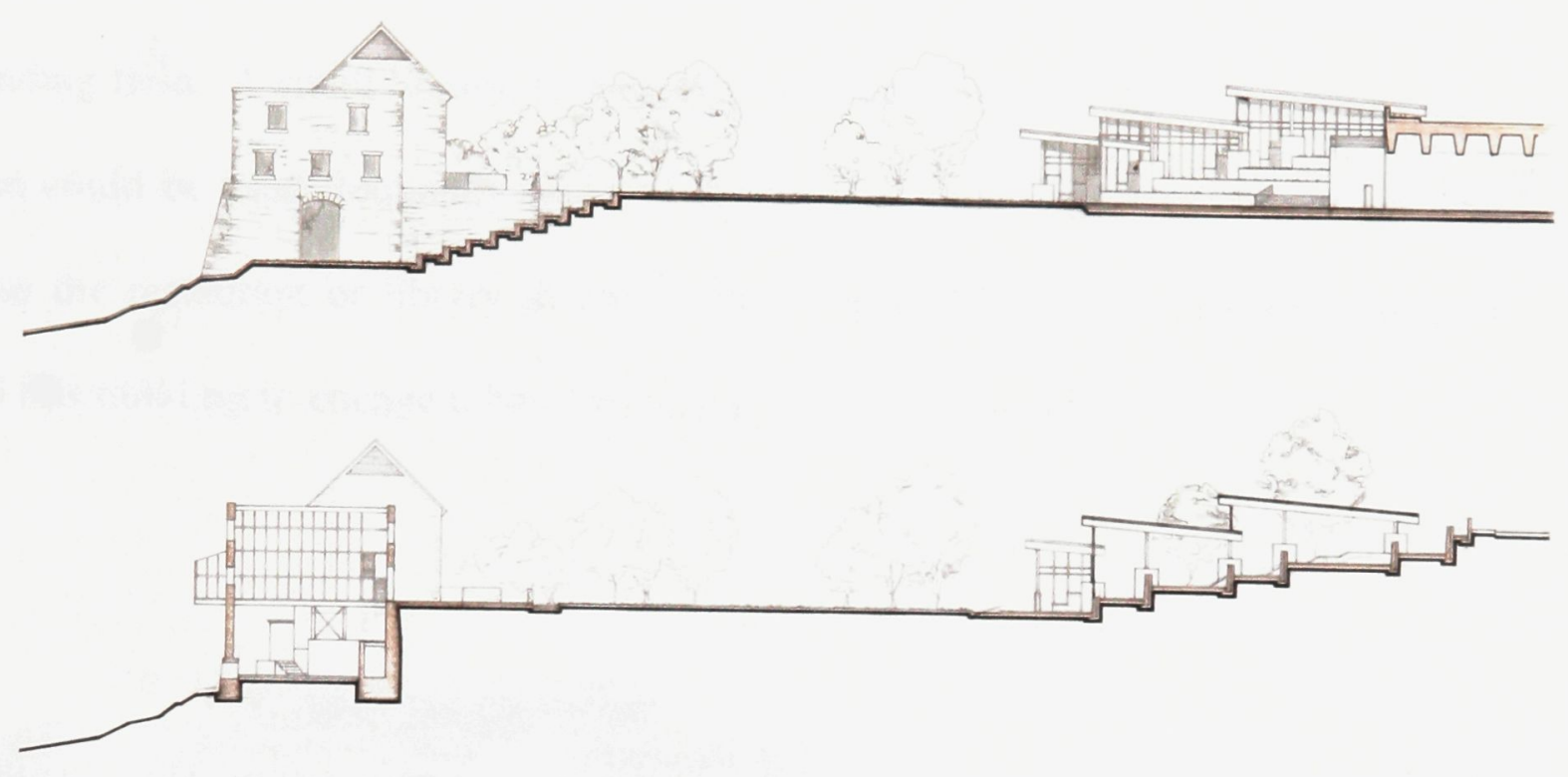

Figure 27- Elevation and Section Through pavilion 2
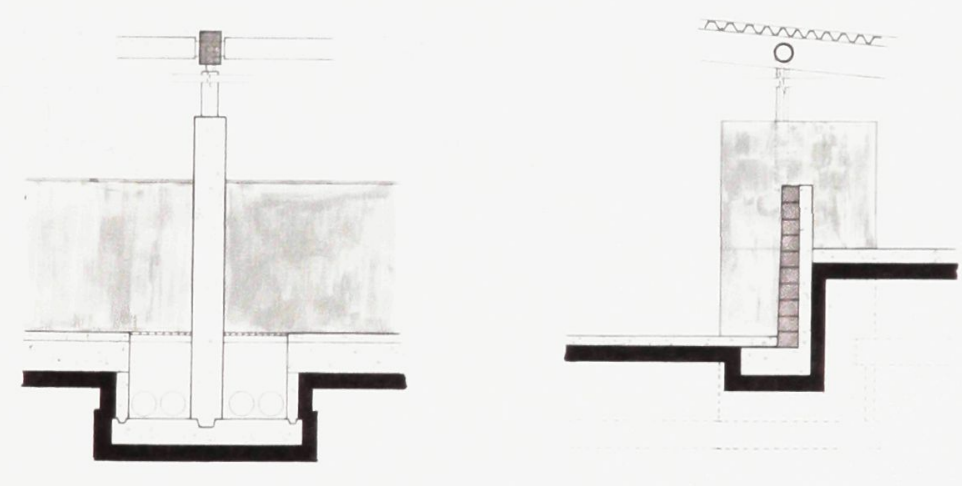

Figure 28- Section Detail of the transition from earth and sky through the Retaining wall and roof.

\footnotetext{
${ }^{45}$ Marco Frascari, ATradition of Architectural Figures: Search For Vita Beata, Body and Building, London: MIT Press. 2002. p. 258
} 
Pavilion 3 is equally referential to the man-mediated topography of the existing site, but unlike Pavilion 2, the entire structure is a heavy earthwork construction: a flat slab concrete structure. The pavilion interacts with the landscape through the walkways and bicycle paths that run through it, green roofs act as lookouts and extensions of the surrounding field. A small library, restaurant, and small theater overlook the water. This pavilion could be used frequently by local residents as well as downtown workers who may use the restaurant or library at lunch time. Like Corbusier's Carpenter Center, I wanted this building to engage urban circulation as much as possible.
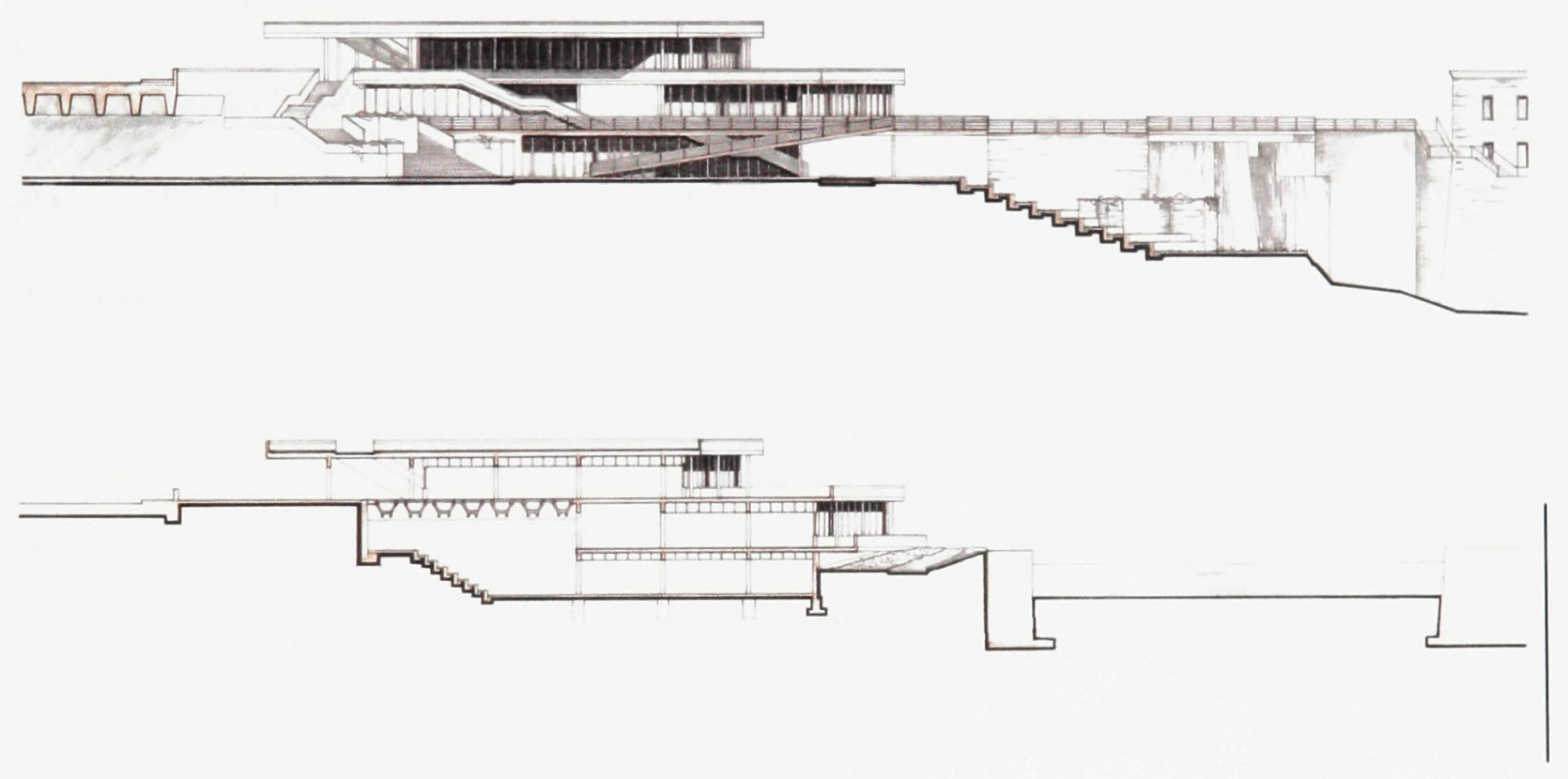

Figure 29- Section Showing Passage over the dam and under the Main Terrace 
The building provides passage for pedestrians through an overpass that connects to the old dam and leads to Victoria Island and downtown Gatineau. The bicycle path which extends to Britannia and the west end of the city borders the river and passes under the restaurant terraces.

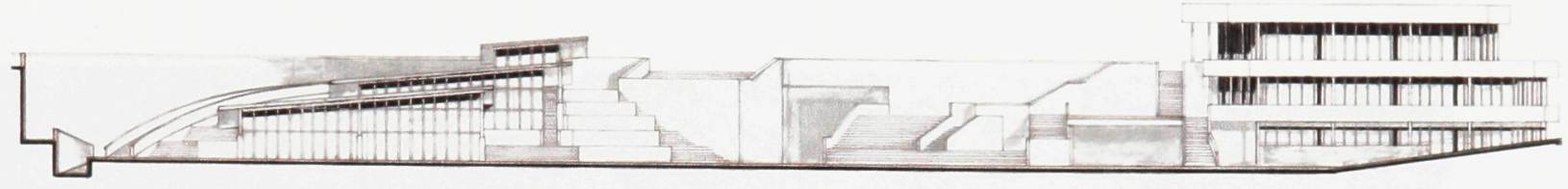

Figure 30-Elevation of Pavilion 3 showing green roof and lookout points to the right

The building's green roofs provide additional space for relaxation, socialization, and contemplation and a view of Parliament Hill for watching fireworks at special occasions.

As a piece of classical Canadian architecture, Pavilion 1 (the Old Mill building), makes an articulate introduction to the site and its history. The building will be used primarily as a visitor center sporting a refreshment counter, a small dining terrace, a presentation center, and a rental shop for bicycles and roller skates. This program was chosen for the building due to its direct access to the bicycle path which extends eastwards to Parliament Hill and westwards to Britannia Park along the Ottawa River. Also, as a heritage building and authentic piece of Ottawa's vernacular architecture, it seems appropriate as an introduction to the city for visitors. The Old Mill was initially 
constructed as an industrial intervention using cuts and pours into the bedrock, to later be mediated by the NCC into a more picturesque extension of the waterfront. The NCC achieved this through the introduction of organic elements and the use of the existing masonry structure as a cliff to cantilever the raised dining lounge. A new walkway is introduced along the water's edge in the same spirit as the dining lounge to bring attention to the stone wall as an extension of the cliff.

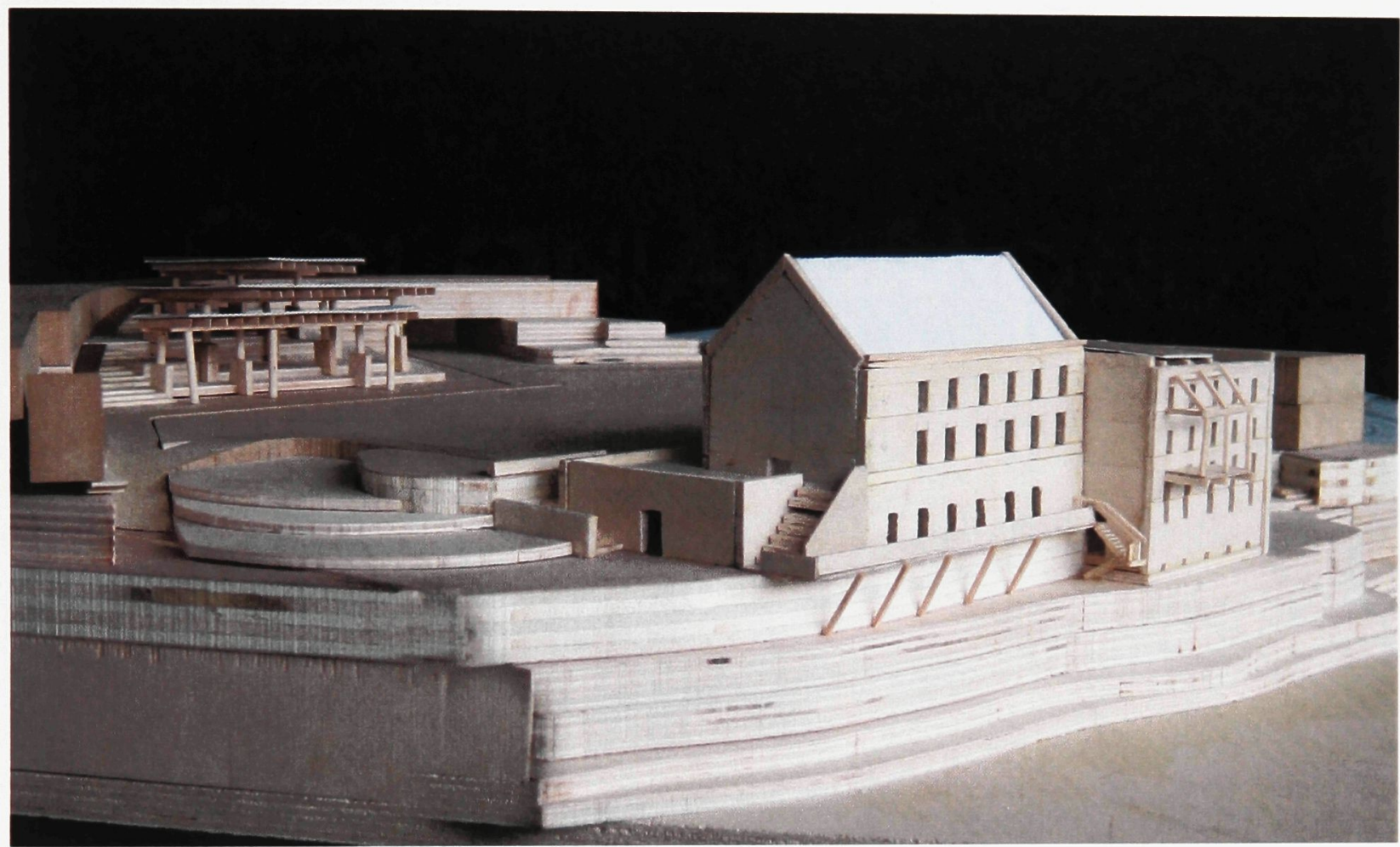

Figure 31- Model photograph showing the cantilever dining terrace and new walkway along the water using the masonry walls as a cliff

The main floor is converted to a counter for tourist information and bicycle rentals. The basement is converted to storage and changing rooms, while the upper floor made into a small museum dedicated to the history of Ottawa and Lebreton Flats. 


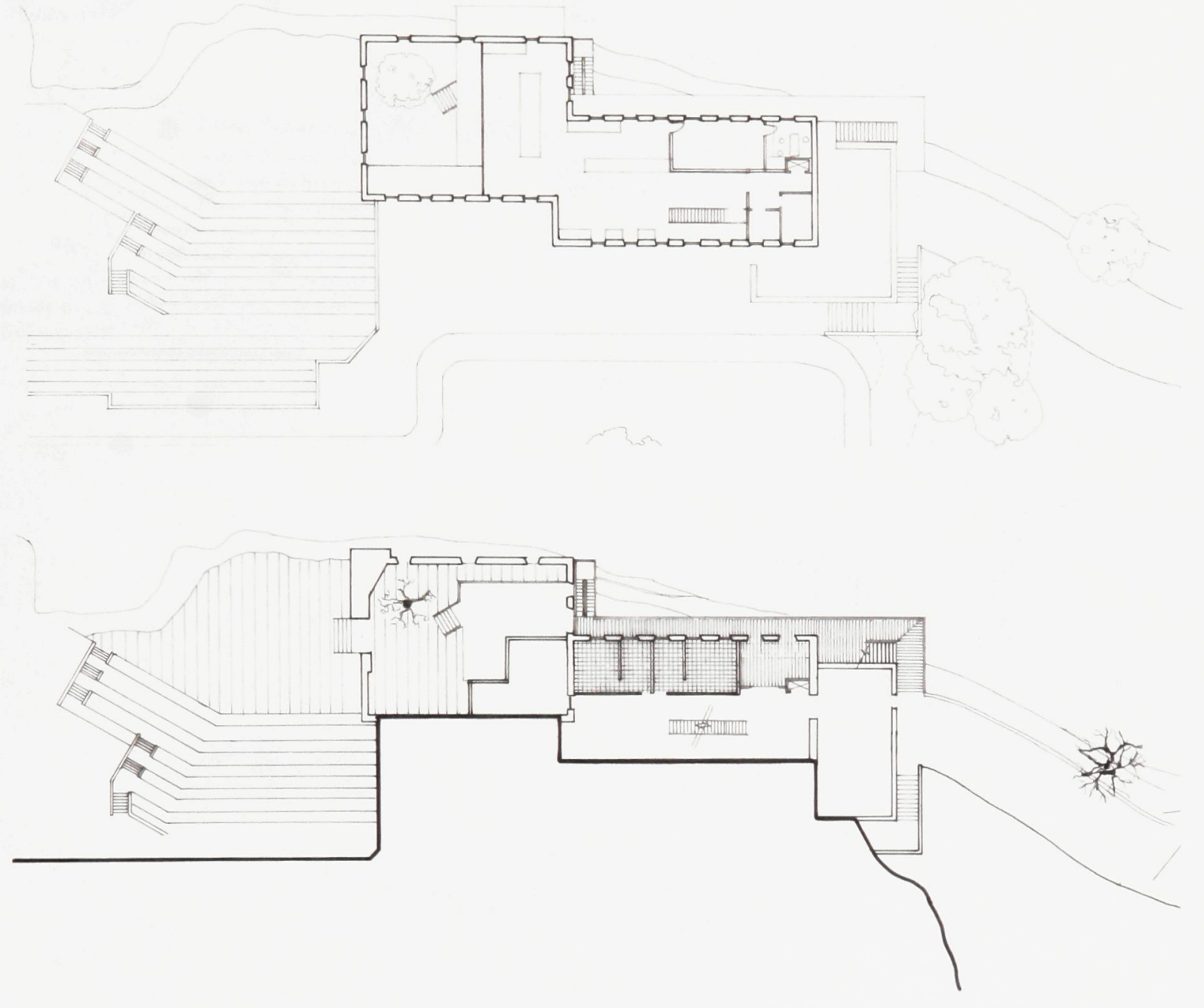

Figure 32- Basement and Second Level Plans of Pavilions 1 


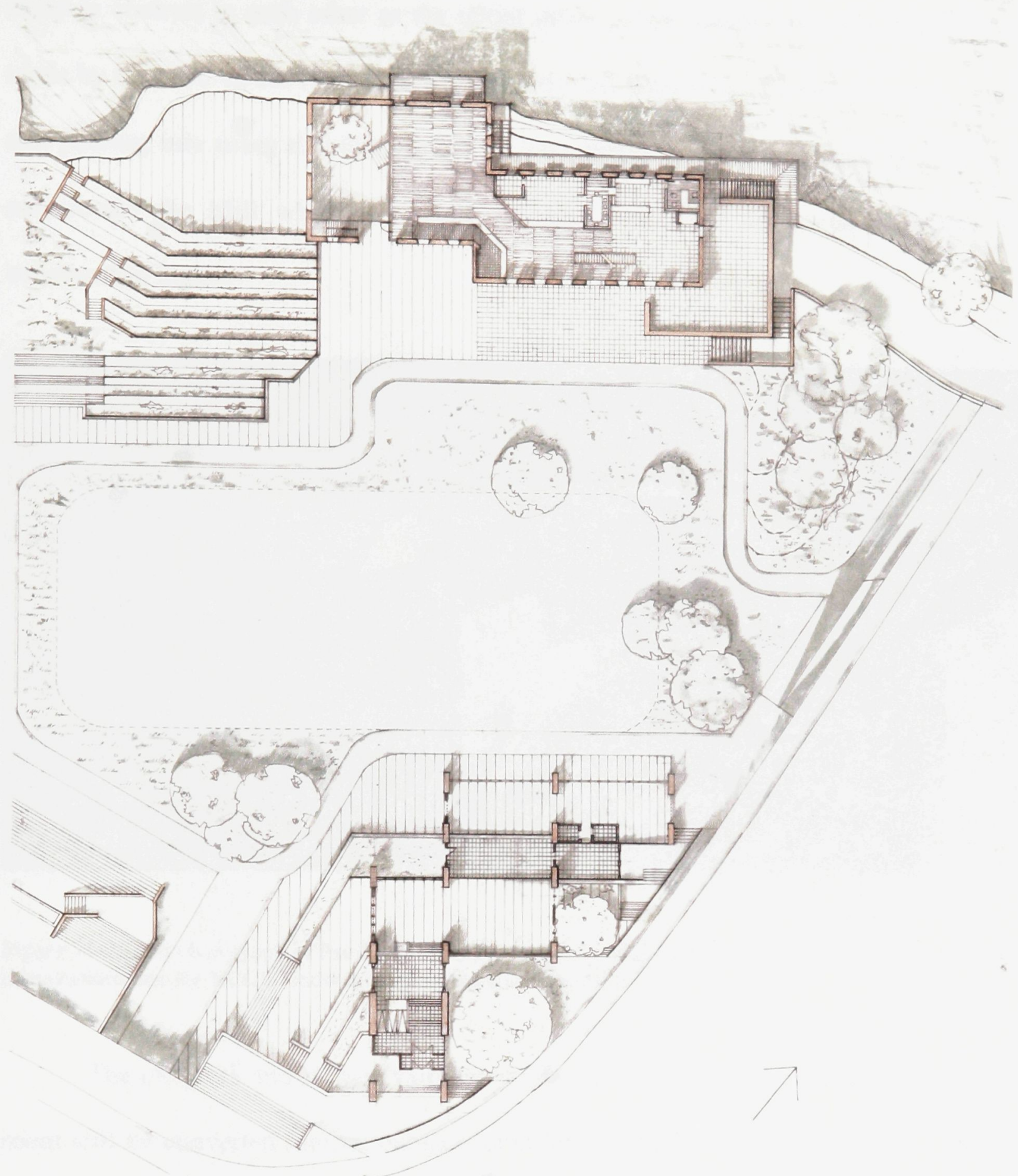

Figure 33- Plans of Pavilions 1and 2 showing dialogue of structural construction and circulation 
The genius loci is strongly present in the dialogue between pavilions 1 and 2. They stand in contrast to each other as the initial move in the construction of pavilion 2 was made by the NCC in the 1960's as they created a hill adjacent to the parkway. By cutting and pouring into using this hill using a similar approach as the industrial builders who constructed the Mill while preserving the mature trees, I am juxtaposing the two construction logics.

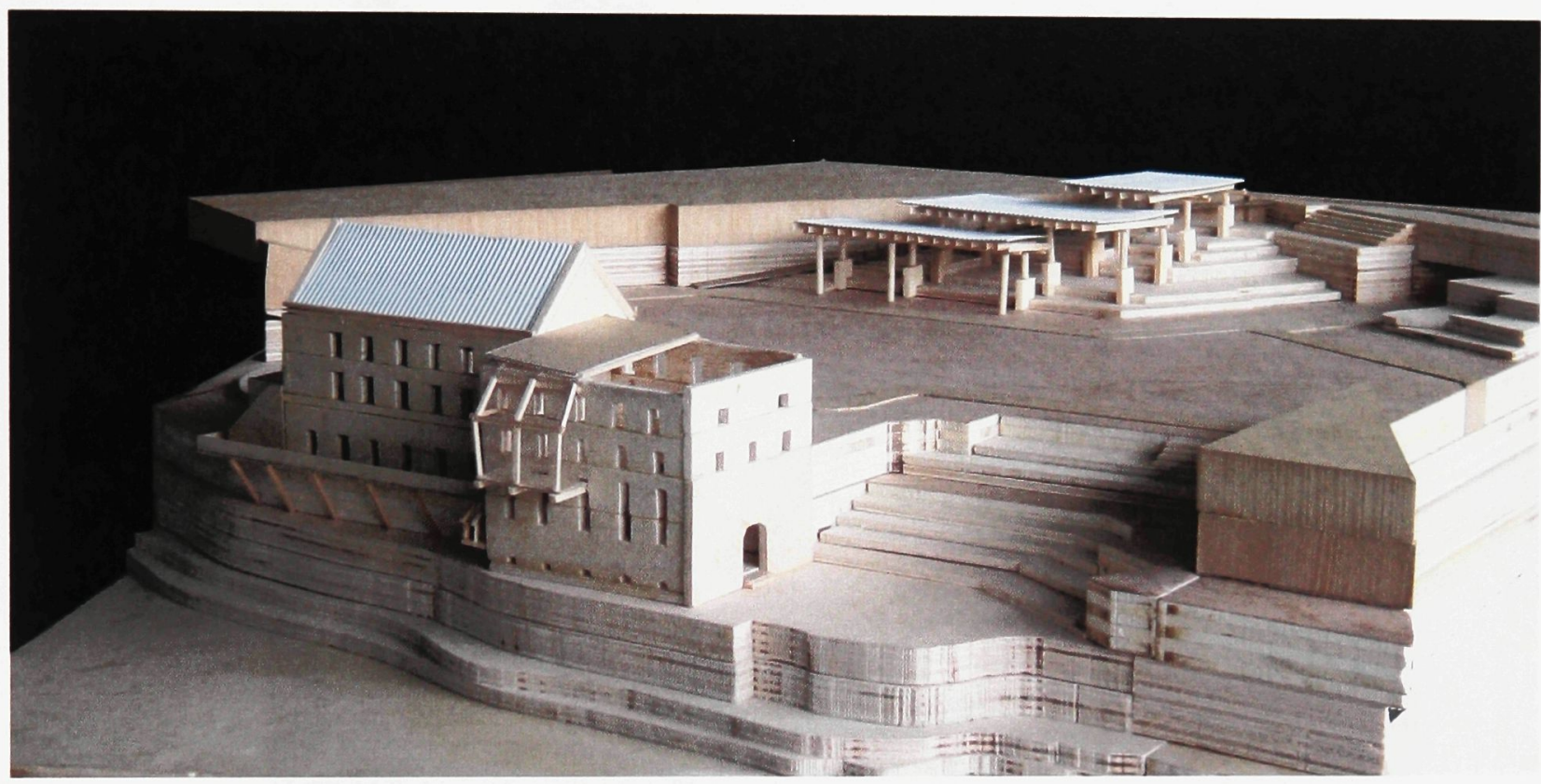

Figure 34- Model photograph of Pavilions 1 and 2 showing the dialogue of construction logic of industrial interventions and the NCC's landscape embellishment movement.

The old work and storage yard carved out of the cliff by the former Mill's turbine room will be converted into an outdoor amphitheater facing the river. It has a similar composition to the overall site at a smaller scale and is ideal for small, intimate events such as children's shows and outdoor weddings. 


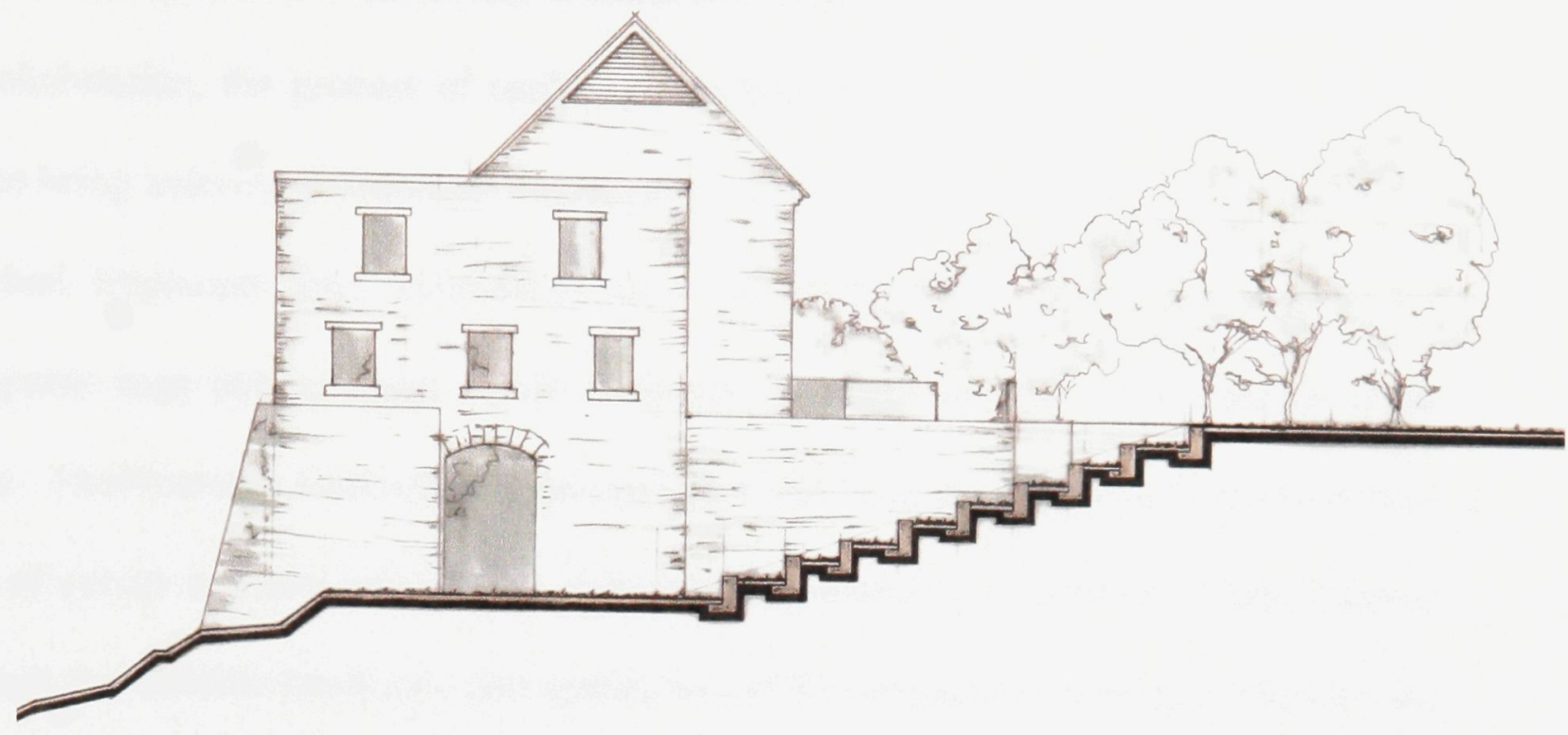

Figure 35- Detail Section of the small theater and former yard

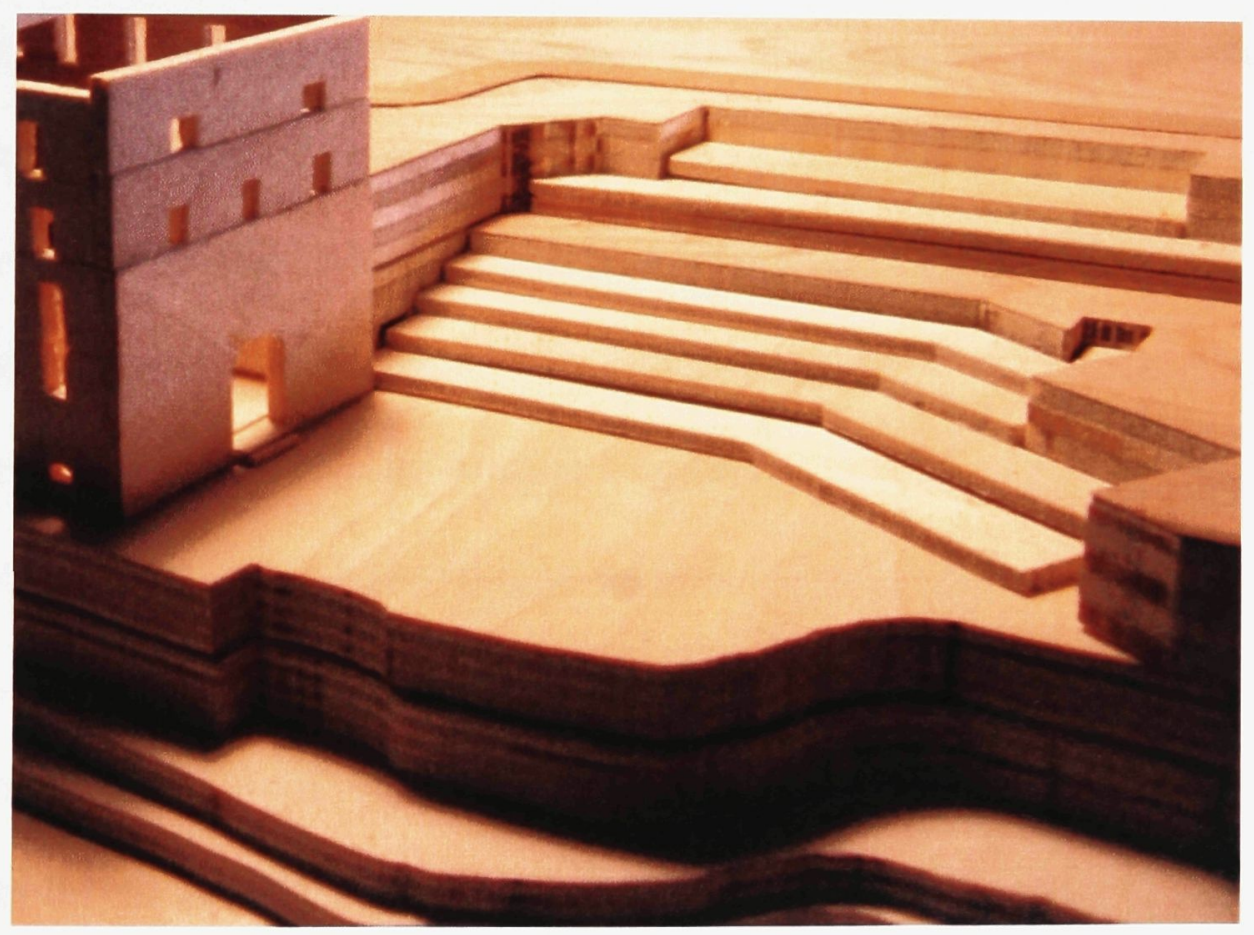

Figure 36- Photograph of the small theater (former work yard) 


\subsection{CONCLUSIONS}

While the true success of any architectural project can only be tested through long term inhabitation, the process of applying a collage of ideologies inherent to the site in order to bring individual historical fragments to a whole has proven to be successful. The individual fragments have maintained their historical weight while becoming active participants in a public space which functions as a community center and an urban theater. The Tectonic Landscape is an approach that owes its existence to the historical traces of events and movements that make up this small site in Lebreton Flats, Ottawa. Although the tectonic landscape and genius loci of this project are specific to the site, the process of generating an eclectic ideological framework based on a collage of local histories can be applied elsewhere.

While the physical collage made of existing fragments in the tectonic landscape was the starting point for this thesis, the ideological collage based on history, culture, and climate is equally important. The new buildings and landscape interventions are all made based on the site's history which suggests a continued dialogue between natural remediation and vernacular architecture. This dialogue in itself illustrates the relationship between critical regionalism and the concept of eclectic collage. In order to maintain integrity to local history without reverting to a single historical movement and repeating the past, it is important to take account of the different layers of information that have accumulated over time. While the region's historic layers provide a large number of potential pieces for the collage, it is important to remember that its eclectic quality comes from a critical analysis and limited selection of the most relevant information. It is this critical and selective process that allows the architect to conceive with an increased 
freedom from strenuous or restrictive ideologies of the past and present while remaining specific to local history, culture, and climate.

I am aware of the skepticism of certain critics with regards to regionalist architecture. Some critics, such as Keith Eggener, are leery of critical regionalism fearing that although the concept begins with good intentions it can revert to a selection of regional identifiers based on personal or stylistic preferences instead of relevance to place and program. ${ }^{46}$ However, in a site loaded with the physical presence of historical fragments, the architect's personal preferences remain under a certain amount of control as the dismissal of the site's "invisible spirit" requires the dismissal of physical evidence.

\footnotetext{
${ }^{46}$ Keith Egenner, "Placing Architecture: A Critique of Critical Rationalism". Journal of Architectural
} Education May 2002. pp 229-237. 


\subsection{BIBLIOGRAPHY}

Allen, Stan, "Plotting Traces of Architecture". Practice, Architecture Technique and Representation, New York: Taylor \& Francis, 2000

Buchanan, Peter, Renzo Piano Building Workshop Complete Works Volume 2, London: Phaidon Press Limited, 1995.

Corner, James, "Terra Flexus", The Landscape Urbanism Reader, New York: Princeton Architectural Press, 2006.

Debanne, Janine. "Flats on the Flats", Canadian Architect, September 2005, available from: $<$ http: $/ /$ www.canadianarchitect.com/issues/ISarticle.asp?id=167489\&story_id=9772 0114749\&issue $=09012005 \& \mathrm{PC}=\&$ RType $=>$

Egenner, Keith, "Placing Architecture: A Critique of Critical Rationalism". Journal of Architectural Education. May 2002. pp 229-237

Fleig, Karl. Alvar Aalto. Switzerland: Birkhauser, 1995.

Frampton, Kenneth. "Towards a Critical Regionalism, Six Points for an Architecture of Resistance". Labour, Work, and Architecture, London: Phaidon Press, 2002.

Frampton, Kenneth The Owl of Minerva, Studies in Tectonic Culture. London: MIT Press, 1995.

Frascari, Marco, "A Tradition of Architectural Figures: Search for Vita Beata", Body and Building, London: MIT Press. 2002

Jenkins, Phil, An Acre in Time: The Enduring Value of Place. Toronto: Macfarlane Walter and Ross, 1996.

KWC Architects Inc, National Capital Commission, Building Condition Assessment Report : Thomas Perkins Mill, (The Old Mill), Ottawa, 2007.

Lefaivre, Liane, Critical Regionalism, New York: Brestel, 2002.

NCC Website, accessed in October 2007.

$<$ http://www.canadascapital.gc.ca/bins/ncc_web_content_page.asp?cid=16300-2044420506-20508\&lang=1>

Norberg-Shultz, Christian, Architecture: Presence, Language, Place. Milano, Italy:

Skira, 2000 
Norberg-Shultz, Christian, Genius Loci: Towards a Phenomenology of Architecture, New York: Rizzoli, 1980.

Phillips, Rhys, "Beautiful Fragments and Sterile Towers" Ottawa Citizen, 2007, available from: $<$ http://www.thefulcrum.ca/node/1234>

Pollio, Vitruvius, -translation by Ingrid D. Rowland, Vitruvius: The Ten Books on

Architecture, New York Cambridge University Press, 1999.

Reed College Academic Website. Accessed April 2008. Available:

$<$ http://academic.reed.edu/humanities/110tech/Theater.html $>$

Rowe, Colin and Koetter, Fred, Collage City, Cambridge: MIT Press, 1978.

Semper, Gottfried, Tectonics, Style in the Technical and Practical Arts. Los Angeles:

Getty Research Institute, 2004.

Shannon Basset, "Logjammed", Canadian Architect, January 2007. Accessed March, 2008. Available from:

$<\mathrm{http}$ ://www.canadianarchitect.com/issues/ISarticle.asp?id=183232\&story_id=19872213 4700\&issue $=01012007 \& \mathrm{PC}=\&$ RType $=>$

Slow Food International Website. Accessed April13, 2008

http://www.slowfood.com/about_us/eng/philosophy

University of Hong Kong, School of Architecture Website, accessed April 2006, available from: www.arch.hku.hk/teaching/cases/duisburg/Duisburg.htm

Waldheim, Charles, "Landscape as Urbanism", The Landscape Urbanism Reader. New York: Princeton Architectural Press, 2006.

Wikipedia, Charles Bridgeman, Accessed March 10, 2008, $<$ http://en.wikipedia.org/wiki/Charles_Bridgeman $>$

Wilson, Alexander, "View From the Road: Recreation and Tourism". The Culture of Nature, Toronto: Between the Lines, 1991. 
APPENDIX

Final Representations 

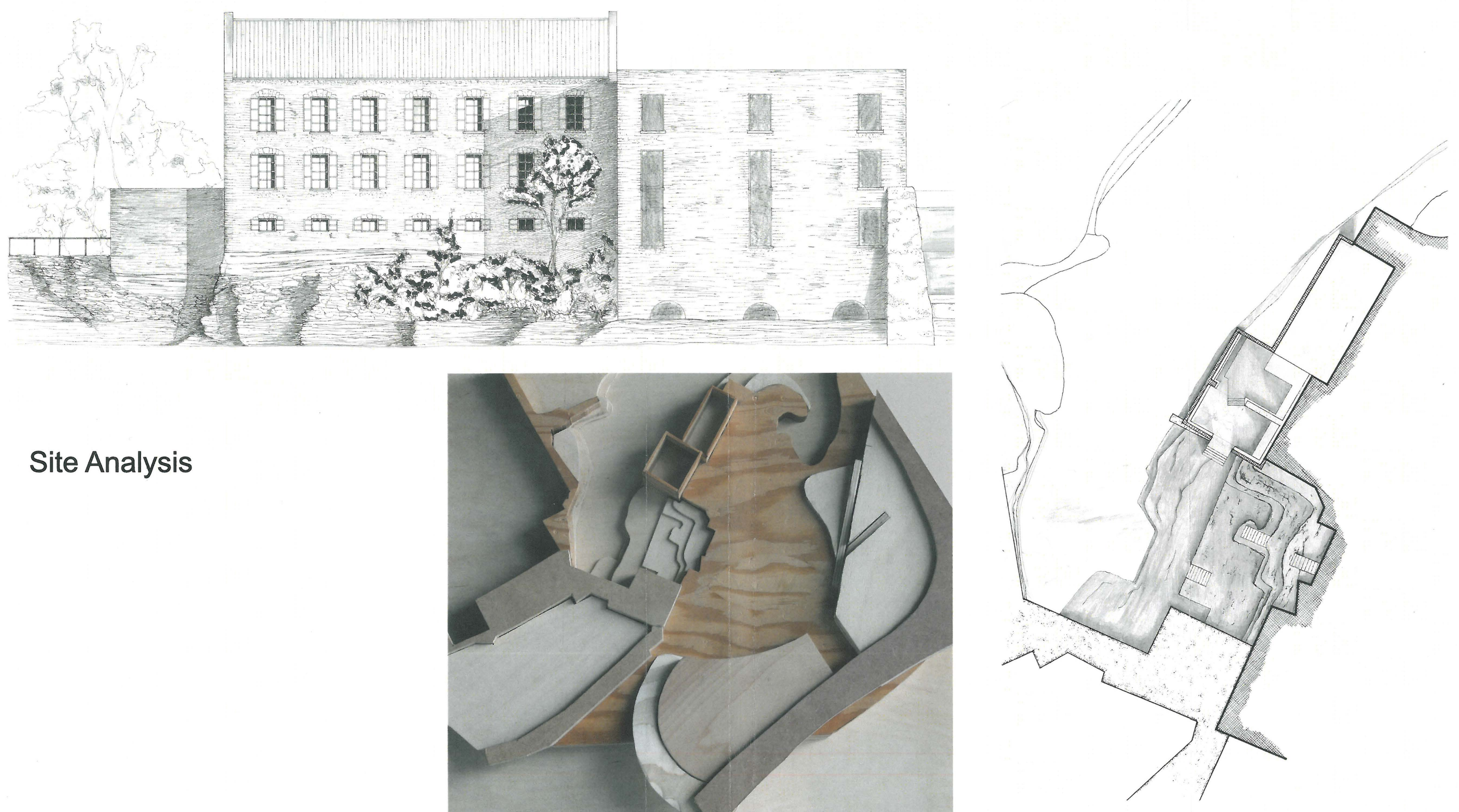

Site Analysis

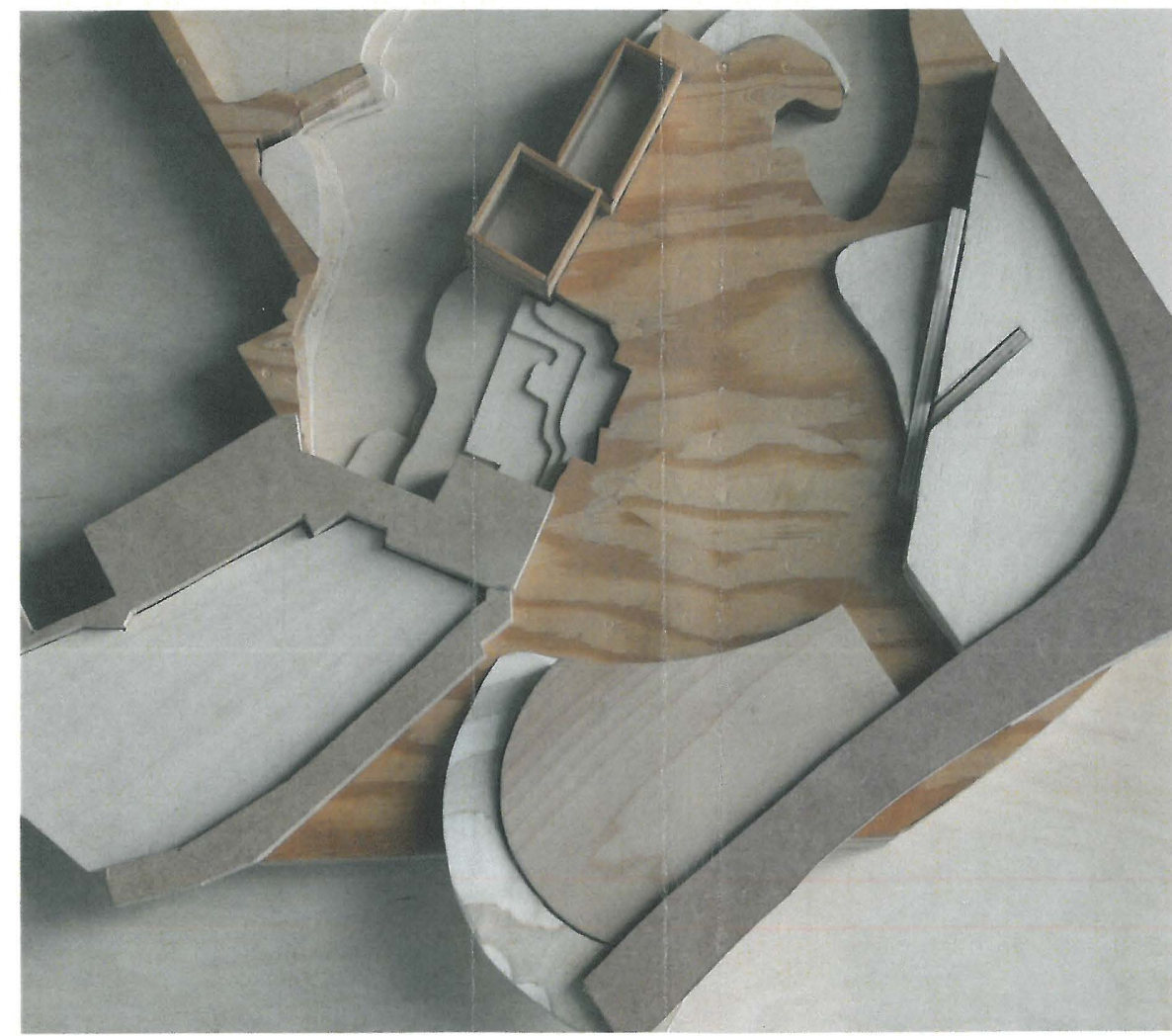




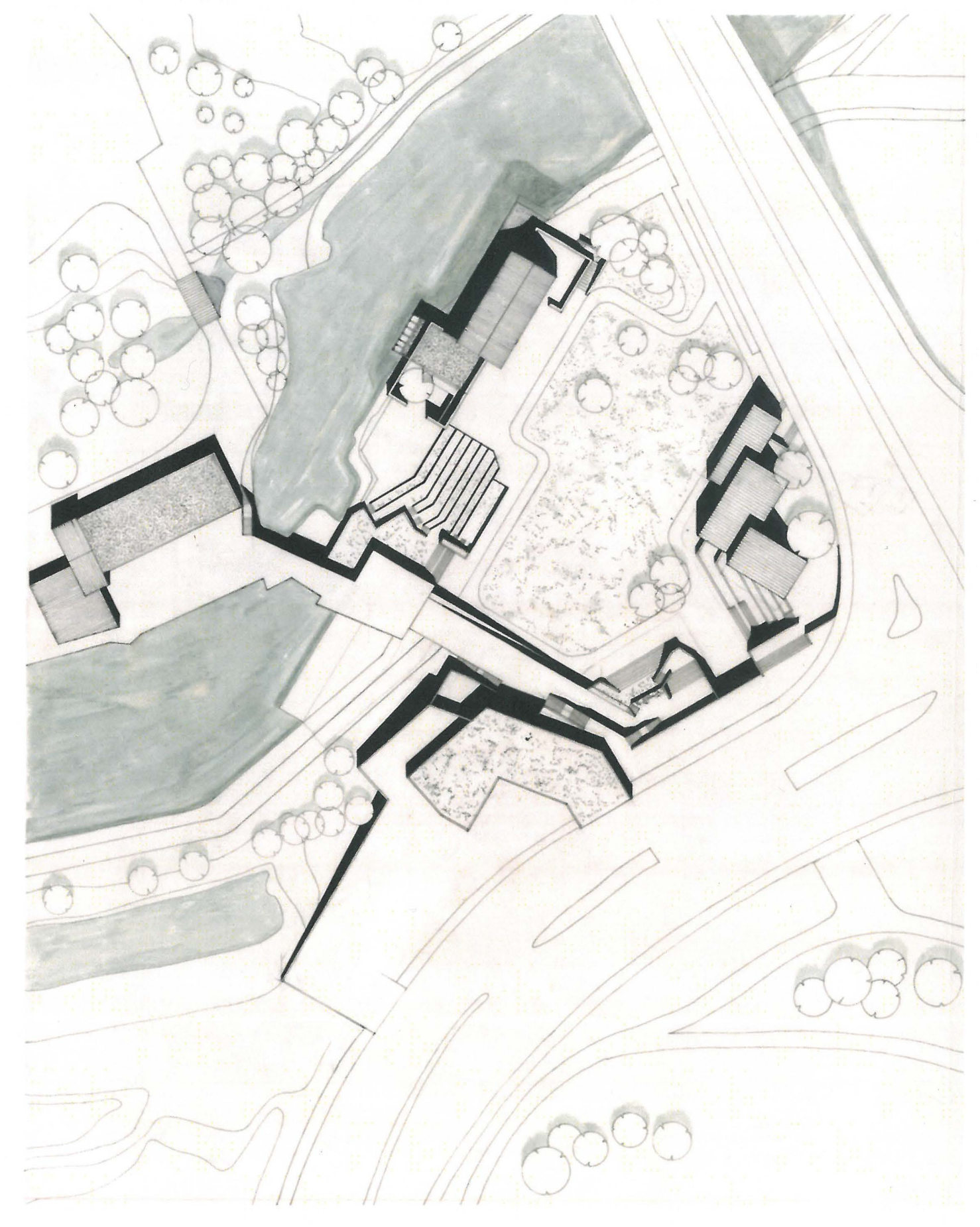

Siteplan-ink on vellum

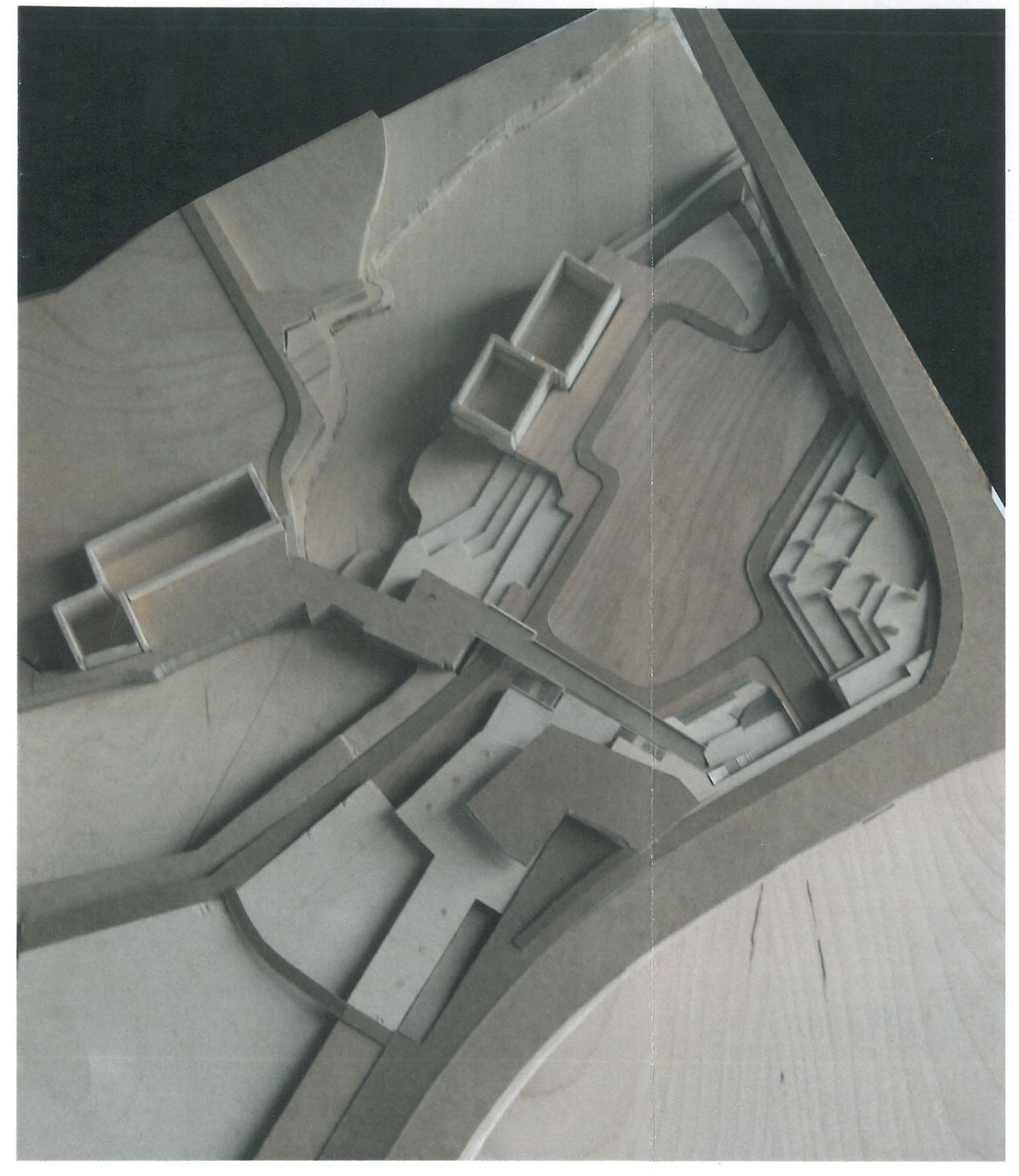

Siteplan wood Collage 


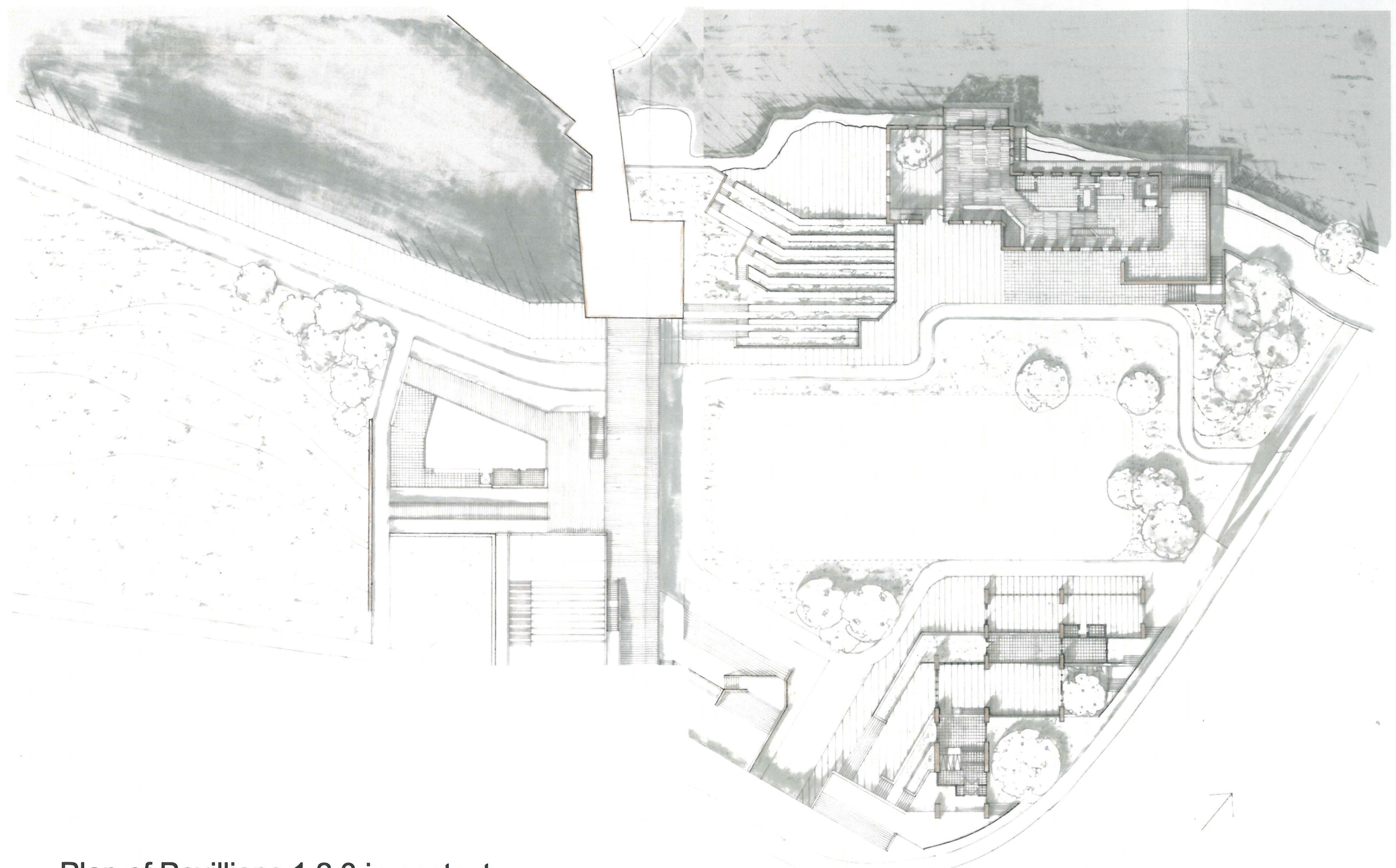

Plan of Pavillions $1,2,3$ in context 


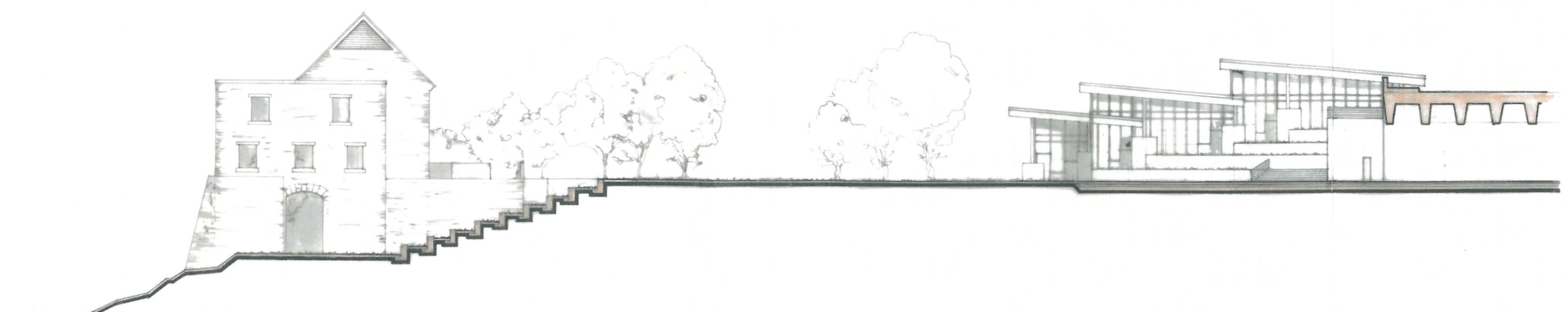

Site Cross-section Showing elevations of Pavilions 1 and 2

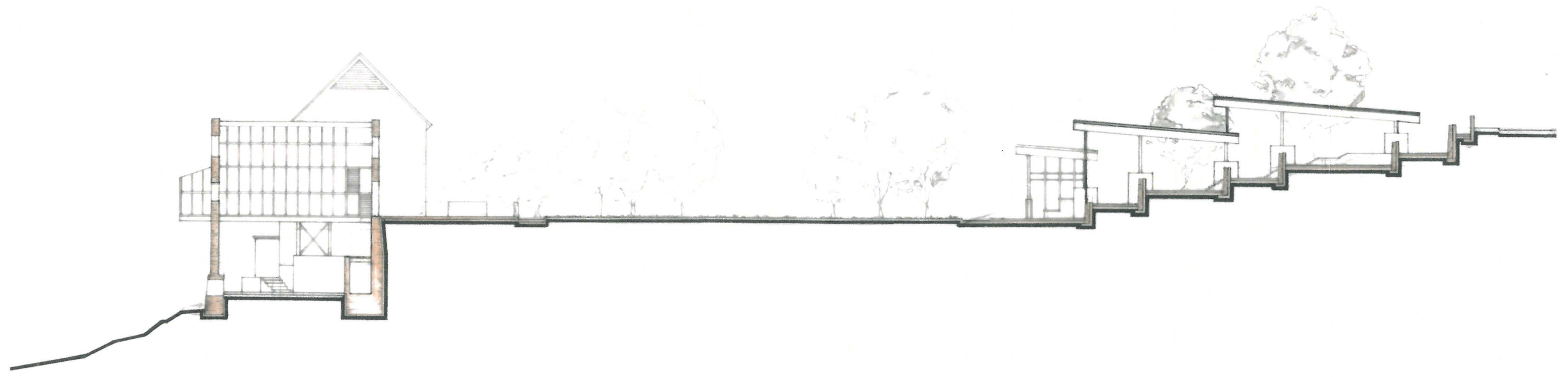

Site Cross-section Showing Cross-Sections of Pavilions 1 and 2 


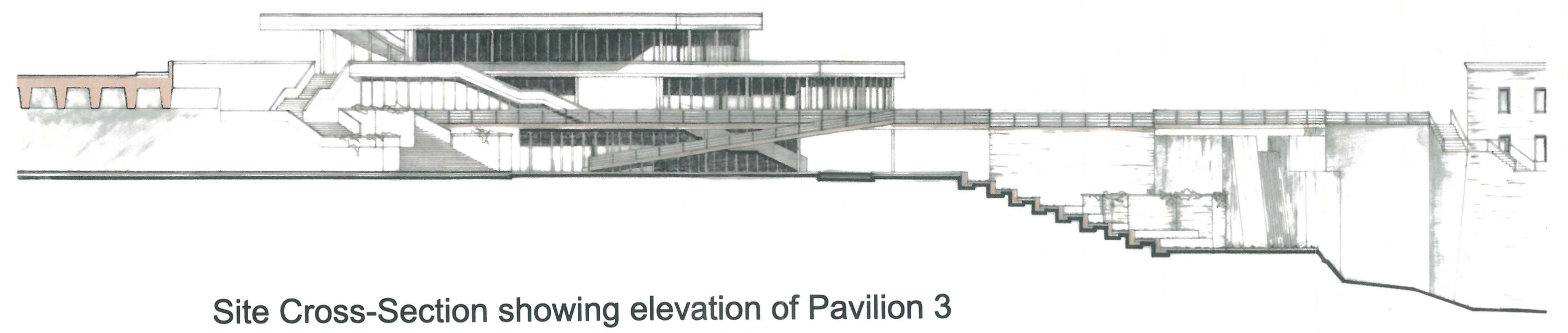

Site Cross-Section showing elevation of Pavilion 3

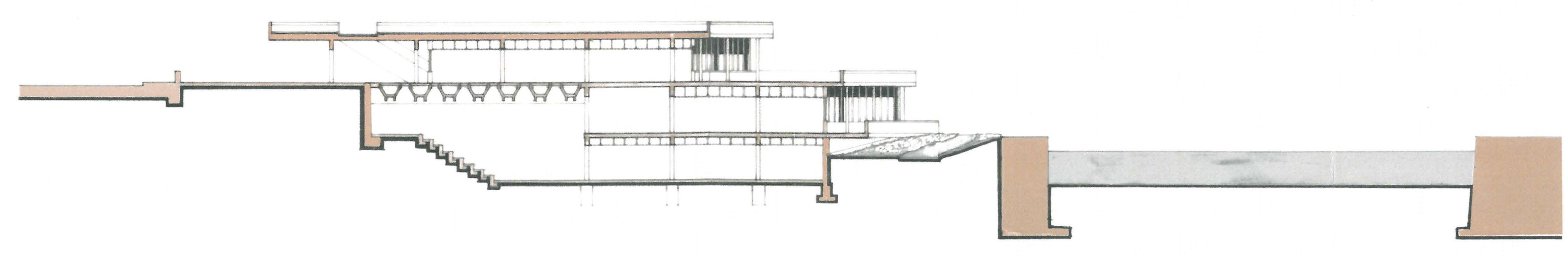

Site Cross-Section showing Section of Pavilion 3 


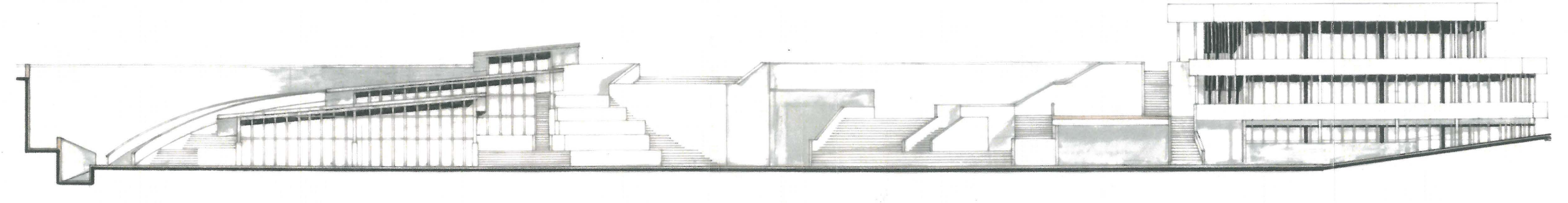

Site Section showing Elevations of Pavilions 2 and 3 

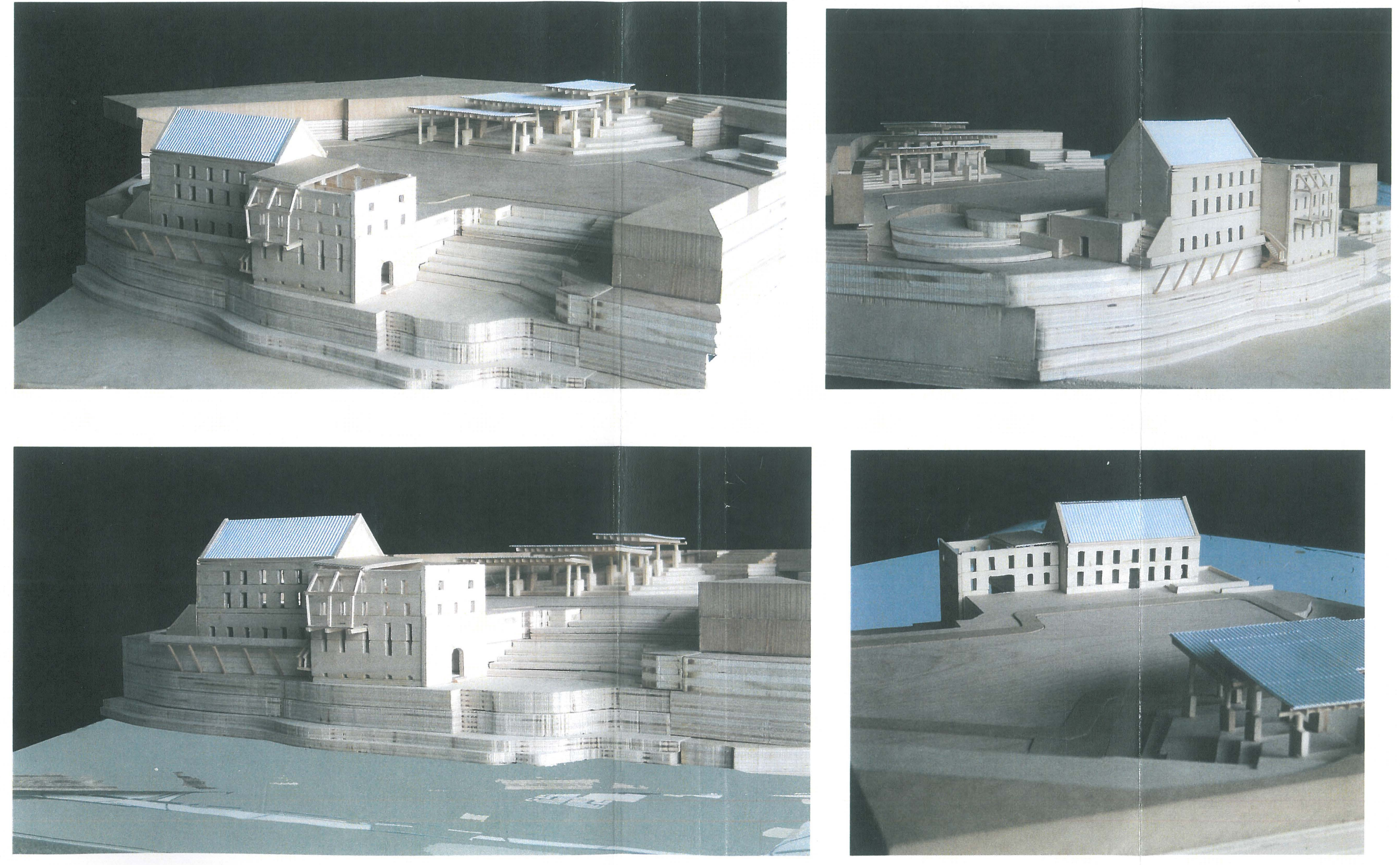